\title{
Task Learning Promotes Plasticity of Interneuron Connectivity Maps in the Olfactory Bulb
}

\author{
는 $L$ \\ and Benjamin R. Arenkiel ${ }^{1,2,4,5}$ \\ ${ }^{1}$ Department of Neuroscience, ${ }^{2}$ Program in Developmental Biology, ${ }^{3}$ Medical Scientist Training Program, ${ }^{4}$ Department of Molecular and Human Genetics, \\ Baylor College of Medicine, and 5 Jan and Dan Duncan Neurological Research Institute at Texas Children's Hospital, Houston, Texas 77030, \\ and ${ }^{6}$ Allen Institute for Brain Science, Seattle, Washington 98103
}

Elucidating patterns of functional synaptic connectivity and deciphering mechanisms of how plasticity influences such connectivity is essential toward understanding brain function. In the mouse olfactory bulb $(\mathrm{OB})$, principal neurons (mitral/tufted cells) make reciprocal connections with local inhibitory interneurons, including granule cells (GCs) and external plexiform layer (EPL) interneurons. Our current understanding of the functional connectivity between these cell types, as well as their experience-dependent plasticity, remains incomplete. By combining acousto-optic deflector-based scanning microscopy and genetically targeted expression of Channelrhodopsin-2, we mapped connections in a cell-type-specific manner between mitral cells (MCs) and GCs or between MCs and EPL interneurons. We found that EPL interneurons form broad patterns of connectivity with MCs, whereas GCs make more restricted connections with MCs. Using an olfactory associative learning paradigm, we found that these circuits displayed differential features of experience-dependent plasticity. Whereas reciprocal connectivity between MCs and EPL interneurons was nonplastic, the connections between GCs and MCs were dynamic and adaptive. Interestingly, experience-dependent plasticity of GCs occurred only in certain stages of neuronal maturation. We show that different interneuron subtypes form distinct connectivity maps and modes of experiencedependent plasticity in the $\mathrm{OB}$, which may reflect their unique functional roles in information processing.

Key words: circuit; interneuron; mitral; olfactory; optogenetics; plasticity

\section{Significance Statement}

Deducing how specific interneuron subtypes contribute to normal circuit function requires understanding the dynamics of their connections. In the olfactory bulb (OB), diverse interneuron subtypes vastly outnumber principal excitatory cells. By combining acoustooptic deflector-based scanning microscopy, electrophysiology, and genetically targeted expression of Channelrhodopsin-2, we mapped the functional connectivity between mitral cells (MCs) and OB interneurons in a cell-type-specific manner. We found that, whereas external plexiform layer (EPL) interneurons show broadly distributed patterns of stable connectivity with MCs, adult-born granule cells show dynamic and plastic patterns of synaptic connectivity with task learning. Together, these findings reveal the diverse roles for interneuons within sensory circuits toward information learning and processing.

\section{Introduction}

Synaptic connectivity maps determine the basic organization and functions of neural circuits (Kandel et al., 2013). Moreover, the plasticity of these connections plays vital roles in circuit develop-

\footnotetext{
Received March 10, 2016; revised July 6, 2016; accepted July 8, 2016.

Author contributions: L.H.,P.S., and B.R.A. designed research; L.H., K.U., I.G., K.B.Q., and K.C. performed research; L.H. and B.R.A. contributed unpublished reagents/analytic tools; L.H., K.U., and B.R.A. analyzed data; L.H., K.U., and B.R.A. wrote the paper.

This work was supported by the McNair Medical Institute, Charif Souki Fund, the National Institute of Neurological Disorders and Stroke-National Institutes of Health (Grant R01NS078294 to B.R.A. and Grant F31NS089178 to K.U.), and the Intellectual and Developmental Disabilities Research Center (NIH Grant U54HD083092. We thank Alex Herman, Cynthia Kim, Paul Pfaffinger, and Roy Sillitoe for helpful input and critical review of this manuscript.

*L.H. and K.U. contributed equally to this work.

L. Huang's present address: Cold Spring Harbor Laboratory, Cold Spring Harbor, New York 11724.
}

ment and sensory adaptation (Fino and Yuste, 2011; Kätzel et al., 2011; Jacob et al., 2012). Therefore, understanding neuronal circuit wiring diagrams with cell-type specificity is essential toward understanding how the brain works. The mammalian olfactory bulb $(\mathrm{OB})$ serves critical roles in a variety of olfactory behavioral processes through a dynamic interplay between principal neurons and different inhibitory interneuron subtypes. However, functional connectivity maps between these neurons, as well as

Correspondence should be addressed to Benjamin R. Arenkiel, Ph.D., Dept. of Molecular and Human Genetics, Jan and Dan Duncan Neurological Research Institute, Baylor College of Medicine, Houston, TX 77030. E-mail: arenkiel@bcm.edu.

DOI:10.1523/JNEUROSCI.0794-16.2016

Copyright $\odot 2016$ the authors $\quad 0270-6474 / 16 / 368856-16 \$ 15.00 / 0$ 
changes they exhibit with experience-dependent plasticity, remain unknown.

In the $\mathrm{OB}$, olfactory information is primarily represented by the mitral/tufted cells (M/TCs). M/TCs receive input from olfactory sensory neurons (OSNs) via synapses within glomeruli. Through OSN receptor selection and expression, glomeruli establish the anatomical foundations of olfactory sensory maps (Buck and Axel, 1991; Mombaerts et al., 1996). Sensory information represented by M/TCs is further refined via input from local inhibitory interneurons (Abraham et al., 2010; Tan et al., 2010). Reciprocal connections between M/TCs and distinct local interneuron subtypes sculpt olfactory information, which is then conveyed to higher brain areas for further processing (Davison and Ehlers, 2011; Ghosh et al., 2011; Miyamichi et al., 2011). Of these local interneurons, granule cells (GCs) are the most abundant (Price and Powell, 1970a, 1970b; Isaacson and Strowbridge, 1998; Schoppa et al., 1998; Chen et al., 2000) and also represent a dynamic population of neurons in the $\mathrm{OB}$ as new GCs continuously migrate and integrate into the bulbar circuitry via adult neurogenesis (Petreanu and Alvarez-Buylla, 2002; Carleton et al., 2003). M/TCs also receive reciprocal input from a population of parvalbumin- and corticotropin-releasing hormone-expressing inhibitory interneurons that reside within the external plexiform layer (EPL) (Fig. 1A). Interestingly, these EPL interneurons show higher unitary synaptic strength and connectivity density onto mitral cells (MCs) than GCs (Lepousez et al., 2010; Huang et al., 2013; Kato et al., 2013; Miyamichi et al., 2013). Previous studies using engineered rabies virus have mapped the anatomical connectivity between MCs and EPL interneurons/GCs (Miyamichi et al., 2013). However, functional connectivity maps between MCs and EPL interneuron populations are lacking. Moreover, given the dynamic addition of new GCs to the $\mathrm{OB}$, understanding how these maps are modified and reshaped by sensory experience remains critical to understanding basic circuit function.

Recently, new methods have been developed to aid in our understanding of the principles of brain wiring and to elucidate patterns of connectivity in brain tissue (Arenkiel and Ehlers, 2009; Murphey et al., 2014), including cell-type-specific reporter expression using conditional viral vectors and light-assisted circuit mapping techniques. In the present study, we investigated the pattern and extent of functional connections between MCs and EPL interneurons or between MCs and GCs by combining optogenetic tools, acousto-optic deflector (AOD)-based scanning microscopy (Iyer et al., 2006), cell-type-specific genetic targeting, and whole-cell electrophysiological recording methods. We found that EPL interneurons and GCs form distinct patterns of connectivity with MCs. Furthermore, we performed behavioral training using an associative olfactory learning paradigm and applied these light-assisted mapping techniques to reveal the plasticity of $\mathrm{OB}$ interneuron connections. We found that EPL interneuron-to-MC connections display fixed patterns of connectivity, whereas GC-to-MC connections exhibit robust experience-dependent plasticity during their maturation. Together, these data reveal differential patterns of connectivity and plasticity between distinctly organized inhibitory interneuron circuits within the $\mathrm{OB}$, highlighting their capacity to perform unique functional roles in olfactory processing and/or olfactory learning.

\section{Materials and Methods}

Experimental animals. All experimental animals were treated in compliance with the Department of Health and Human Services and the Baylor College of Medicine Institutional Animal Care and Use Committee guidelines. Crh-Cre (Taniguchi et al., 2011), ROSA-lsl-tdTom (Arenkiel et al., 2011), Dlx5/6-Cre (Monory et al., 2006), and Thy1-ChR2 mice (Arenkiel et al., 2007) have been described previously. Both female and male mice were used for this study.

Viral injection and EdU pulsing. Adeno-associated virus (AAV) serotype 2/9 encoding flexed ChR2 and flexed tdTomato plasmid constructs were obtained from the University of Pennsylvania Vector Core and packaged in-house. Then, $630 \mathrm{nl}$ of AV $\left(2.5 \times 10^{12}\right.$ viral particles $\left./ \mathrm{ml}\right)$ was injected into the $\mathrm{OB}$ (from bregma: $\mathrm{ML}, \pm 0.9 \mathrm{~mm}$; AP, $3.82 \mathrm{~mm}$; and $0.5 \mathrm{~mm}$ down from the surface of the OB) of Dlx5/6-Cre or Dlx5/6-Cre; Thy1-ChR2 mice using glass injection pipettes and a Nanoject II (Drummond Scientific) at a rate of $63 \mathrm{nl} / \mathrm{s}$ at $15 \mathrm{~s}$ intervals to obtain uniform labeling of GCs.

For EdU pulsing experiments, adult Dlx5/6-Cre mice received one dose of EdU intraperitoneally (Invitrogen, $50 \mathrm{mg} / \mathrm{kg}$ ). Then, 7, 21, 45, and $60 \mathrm{~d}$ after EdU pulsing, AAV flex GFP was injected into the OB as described above. Mice were killed $14 \mathrm{~d}$ after injection for imaging.

Intrinsic signal imaging. Intrinsic signal imaging was performed based on previously described methods (Lin da et al., 2006). A monochrome CMOS camera MV1-D1312-40-G2-12 (Photonfocus) was focused on the glomerular layer to record OB activity. An LED with $630 \mathrm{~nm}$ light (Thorlabs) was used for illumination. Odor stimuli were presented with an olfactometer that controls airflow through different vials containing odors and continuous oxygen was mixed with odor stimuli before delivery. Each odor was presented for $10 \mathrm{~s}$, with 1 min intervals between 2 stimuli. Images were taken from $3 \mathrm{~s}$ before odor stimulation to $7 \mathrm{~s}$ after odor stimulation, 20 frames in total each for $1 \mathrm{~s}$. Average pixel intensity during 6-9 s (3-6 s after odor stimulus onset) was subtracted from average during 2-3 s (1 s before odor stimulus) and then divided by the average during $2-3 \mathrm{~s}$ for normalization. The odor responses were then averaged over 5-20 trials for each odor. The final image was Gaussian filtered $(\sigma=50 \mu \mathrm{m})$. For imaging, labeling, and subsequent recording, we imaged the responding area to propionic acid (first $1 \mathrm{~mm}$ ) in the medial-dorsal domain and the responding area to butanol (first $1 \mathrm{~mm}$ ) in the lateral-dorsal domain. We then immediately killed the animal, dissected the brain, and prepared coronal slices. Because we made 300 $\mu \mathrm{m}$ slices, we only used the first three sections for Go odor and NoGo odor cell recording. For Go odor cells, we recorded from neurons in the dorsal-medial part of these slices and, for NoGo cells, we recorded from neurons in the dorsal-lateral part. We recorded neurons in posterior sections or in ventral regions for "nonactivated cells." We also injected Fast Green or DiI to label the area after intrinsic imaging, using a Nanoject to inject the dyes into the corresponding areas as shown by intrinsic imaging, and collected dye-labeled sections separately when slicing the brain.

Electrophysiology and optogenetic photostimulation. Coronal OB slices $(300 \mu \mathrm{m})$ were prepared from Crh-Cre;ROSA-lsl-ChR2 mice, Thy1ChR2;Crh-Cre;ROSA-lsl-tdTom mice, Dlx5/6-Cre;AAV flexed ChR2 mice, or Thy1-ChR2;Dlx5/6-Cre;AAV flexed tdTom mice. Animals were deeply anesthetized using isoflurane and perfused intracardially with icecold artificial CSF (ACSF) containing the following (in mM): $122 \mathrm{NaCl}, 3$ $\mathrm{KCl}, 1.2 \mathrm{NaH}_{2} \mathrm{PO}_{4}, 26 \mathrm{NaHCO}_{3}, 20$ glucose, $2 \mathrm{CaCl}_{2}$, and $1 \mathrm{MgCl}_{2}$ at 305-310 mOsm, pH 7.3. Brains were dissected, rapidly embedded in low-melting-point agarose, and sectioned in ice-cold oxygenated (5\% $\mathrm{CO}_{2}, 95 \% \mathrm{O}_{2}$ ) dissection buffer containing the following (in $\mathrm{mm}$ ): 87 $\mathrm{NaCl}, 2.5 \mathrm{KCl}, 1.6 \mathrm{NaH}_{2} \mathrm{PO}_{4}, 25 \mathrm{NaHCO}_{3}, 75$ sucrose, 10 glucose, 1.3 ascorbic acid, $0.5 \mathrm{CaCl}_{2}$, and $7 \mathrm{MgCl}_{2}$, recovered $\left(15 \mathrm{~min}\right.$ at $37^{\circ} \mathrm{C}$ ) in oxygenated ACSF, and acclimated at room temperature for $10 \mathrm{~min}$ before electrophysiological recordings.

Borosilicate glass electrodes (Sutter Instruments) were used for wholecell patch-clamp recordings. Electrodes were pulled with tip resistances between 6 and $10 \mathrm{M} \Omega$ and filled with internal solution containing the following (in $\mathrm{mm}$ ): for current-clamp conditions: $120 \mathrm{~K}$-gluconate, 5 $\mathrm{KCl}, 2 \mathrm{MgCl}, 0.05$ EGTA, $10 \mathrm{HEPES}, 2 \mathrm{Mg}$-ATP, $0.4 \mathrm{Mg}$-GTP, and 10 creatine phosphate, 300-310 mOsm, $\mathrm{pH} 7.3$; for IPSC voltage-clamp conditions: $89 \mathrm{CsMeSO}_{3}, 46 \mathrm{CsCl}, 1 \mathrm{MgCl}_{2}, 0.16 \mathrm{CaCl}_{2}, 0.2 \mathrm{EGTA}, 15$ HEPES, 4 Na-ATP, 0.4 Na-GTP, 15 TEA-Cl, and 14 creatine phosphate, 300-310 mOsm, $\mathrm{pH}$ 7.3; and for EPSC voltage-clamp conditions: 110 $\mathrm{CsMeSO}_{3}, 0.2$ EGTA, $4 \mathrm{NaCl}, 30$ HEPES, 2 Mg-ATP, 0.3 Na-GTP, 14 

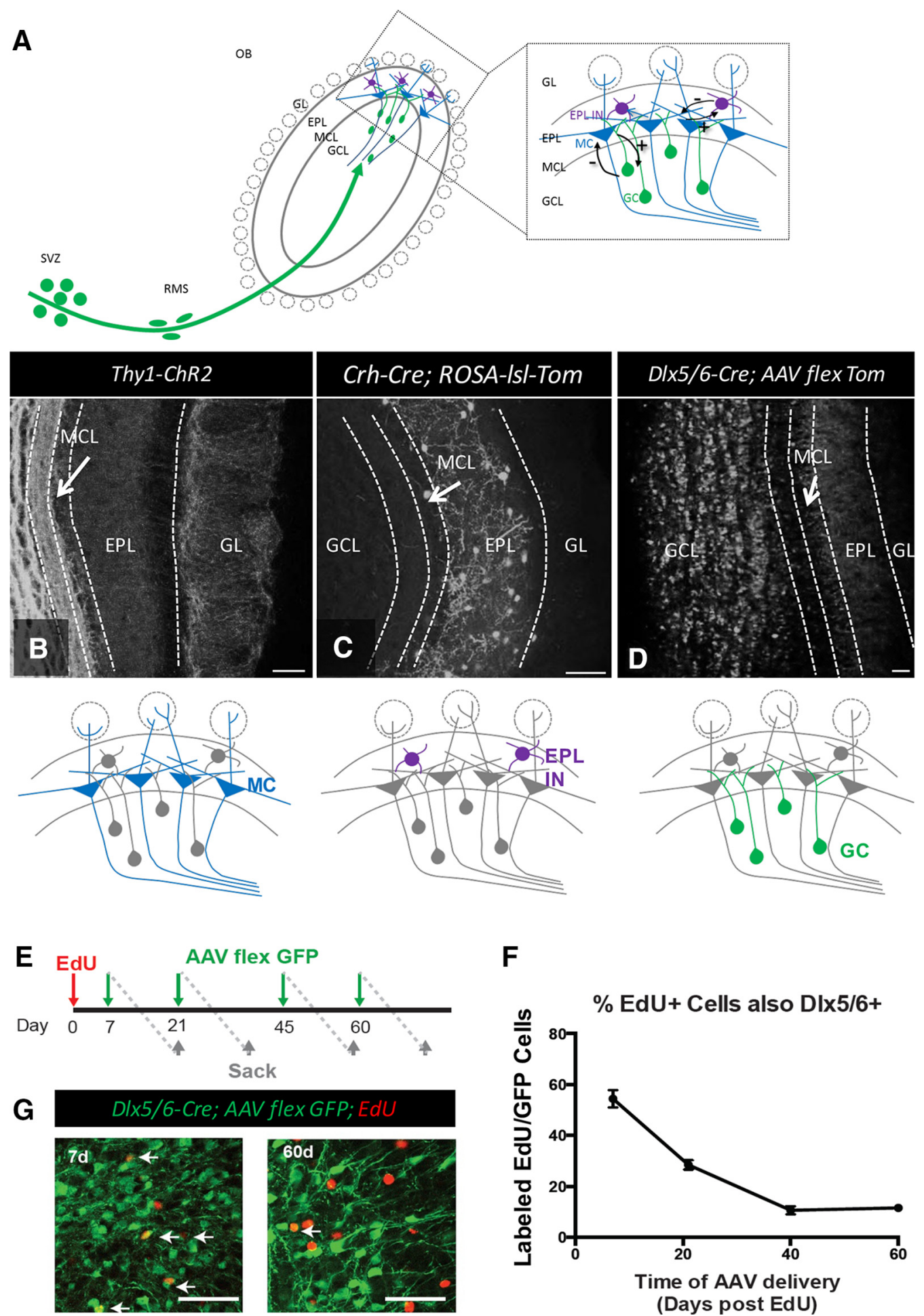

Figure 1. Cell-type-specific genetic drivers to target and manipulate neuronal subtypes in the OB. A, Diagram showing the architecture of neural circuits in the OB. MCs form reciprocal connectivity with both GCs and EPL interneurons. During adulthood, GCs are continuously generated from the stem cell niche in the subventricular zone, migrate along the rostral migratory stream, and integrate into OB circuits. SVZ, Subventricular zone; RMS, rostral migratory stream; GL, glomerular layer; IN, interneuron; + , excitation; - , inhibition. B, MCs are targeted using Thy 1-ChR2 mice for MC-specific photoactivation. Scale bar, $100 \mu \mathrm{m}$. C, EPL interneurons are targeted using a Crh-Cre driver line. Scale bar, $100 \mu \mathrm{m} . \mathbf{D}, \mathrm{GC}$ are targeted using a D/x5/6-Cre driver line (3 weeks after viral injection). Scale bar, $100 \mu \mathrm{m}$. E-G, Targeting of maturing GCs using the D/x5/6-Cre driver line. E, Diagram showing the experimental timeline. All the experiments were done in D/x5/6-Cre mice. $\boldsymbol{F}$, Expression of GFP and EdU in GCS. AAV flex GFP particles were injected into the OB $7 \mathrm{~d}-60 \mathrm{~d}$ after EdU pulse. G, Quantification of EdU and GFP labeling in GCs. Arrows mark GCs labeled by both GFP and EdU. Scale bar, $50 \mu \mathrm{m}$.

creatine phosphate, and 5 QX314, 300-310 mOsm, pH 7.3. To visualize recorded cells, Alexa Fluor 594 (100 $\mu \mathrm{m}$; Invitrogen) was loaded into internal solutions. During recordings, coronal OB slices were placed in a recording chamber mounted on an upright microscope (BX50WI;
Olympus) and perfused with oxygenated ACSF at room temperature. Cells were visualized under differential interference contrast imaging. Data were obtained via a Multiclamp 700B amplifier, low-pass Bessel filtered at $4 \mathrm{kHz}$, and digitized (Clampex; Molecular Devices). 
To record neurons selectively in areas that responded to specific odors, we used gross coordinates in the caudal-rostral, medial-lateral, and dorsal-ventral axes. We grouped cells in the rostral-medial-dorsal regions as "propionic acid cells," cells in the rostral-lateral-dorsal regions as "1-butanol cells," and cells in all other regions as "nonactivated cells." Neurons were randomly chosen from these regions across multiple coronal sections during recording.

A BLM-Series $473 \mathrm{~nm}$ blue laser system (Spectra Services) was used to generate laser light. A neutral density filter (Thorlabs) was used to attenuate laser intensity. Two orthogonally mounted AODs (LS55-V; Isomet) were used to produce arbitrary random-access $2 \mathrm{D}$ scan patterns. To generate acoustic waves for deflectors, two deflector drivers (Intra Action) were implemented. Custom software written in MATLAB (The MathWorks) was used to control output voltages through a D/A converter (National Instruments) connected to the deflector drivers. A scan angle magnification telescope was used to increase scan range to fit the objective's field of view. Finally, the AOD scanning beam was coupled into the upright microscope as described above. For circuit mapping, stimulation sites were programmed at grid points spaced by $30 \mu \mathrm{m}$ in OB slices with $10 \mathrm{~ms}$ duration and $100 \mathrm{~ms}$ intervals. To elicit action potentials in ChR2 + cells with high fidelity and spatiotemporal resolution, we optimized the laser intensity ( $\sim 20 \mathrm{~mW} / \mathrm{mm}^{2}$ for GC-to-MC mapping and $\sim 40 \mathrm{~mW} / \mathrm{mm}^{2}$ for others) to meet the requirements for photoactivation in different scenarios (cell-type specificity and/or genomeencoded vs virus-encoded ChR2 + expression).

Olfactory associative learning training. Mice were water restricted to no less than $85 \%$ of their baseline consumption $4 \mathrm{~d}$ before preliminary training. Water was provided at $1 \mathrm{ml} / \mathrm{d}$ during the water restriction period. Then, mice were divided into control, pseudotrained, or trained groups. Mice in the "trained" group were subjected to a Go-NoGo paradigm in a behavioral chamber with nose pokes (Med Associates). Mice were first trained to poke into the odor port with their noses for at least $400 \mathrm{~ms}$ and then to lick the water port to receive a water reward within $5 \mathrm{~s}$. After preliminary training sessions $(\sim 30-60 \mathrm{~min} / \mathrm{d}$ for $\sim 5-6 \mathrm{~d})$, mice were trained to respond to the Go odor stimulus by licking or to respond to the NoGo odor stimulus by refraining from licking. The mice needed to sample the odors for at least $300 \mathrm{~ms}$ before responding and to respond within $5 \mathrm{~s}$ after odor port poking. If the mice incorrectly licked the water port on a NoGo trial, there was a $4 \mathrm{~s}$ timeout punishment. Go and NoGo stimuli were presented to the mice in random sequences during training. Mice were trained for 20 trials per block, and $\sim 10-20$ blocks per day. A percentage of correct responses $>85 \%$ was considered the threshold criteria for trained mice. For the control group, mice were water restricted, but without associative learning training. For the pseudotrained group, mice were trained in a similar way as the trained group, with the exception that the association between the reward/punishment and the odors was randomized. We used $10 \% 1$-butanol and $10 \%$ propionic acid (v/v) as odor stimuli. In the trained group, the valence of each odor was randomly assigned for each individual mouse, but kept consistent for a given animal. Pure monomolecular odorants were diluted in $5 \mathrm{ml}$ of mineral oil. All odors were purchased from Sigma-Aldrich.

Confocal imaging. For confocal imaging, animals were deeply anesthetized using isoflurane, followed by intracardial perfusion of PBS and $4 \%$ PFA. Brains were dissected, postfixed in 4\% PFA for $1 \mathrm{~h}$ at room temperature, and then processed in $\mathrm{PBS}$ overnight at $4^{\circ} \mathrm{C}$. OBs were sectioned at $50 \mu \mathrm{m}$ using a Compresstome (Precisionary Instruments) and mounted with Vectashield mounting medium. Imaging was performed using a Leica TCS SPE confocal microscope under a $10 \times$ objective. Antibodies were not used to enhance the signals.

Data analysis. For connectivity mapping experiments, we considered a synaptic event as an evoked postsynaptic current (PSC) if it met two criteria: (1) the amplitude was $>5 \mathrm{pA}$ and (2) the onset of the PSC was within $20 \mathrm{~ms}$ after the onset of laser stimulation. Each trace was analyzed and the evoked PSC amplitude and probability for each stimulation spot were calculated. A stimulation spot was considered as "connected" if the probability was $>0.4$. The average evoked PSC amplitude for a certain spot was calculated by averaging the amplitudes of all evoked PSCs during multiple trials (those trials failing to evoked PSCs were excluded). For normalization, all amplitude values were normalized to the highest value for each cell.

\section{Results}

\section{Targeting OB neuronal subtypes using cell-type-specific genetic manipulations}

To map the functional connectivity between MCs and EPL interneurons or GCs, we implemented cell-type-specific optogenetic manipulations. For this, we used Thy1-ChR2 (Channelrhodopsin-2) mice for mitral-cell-specific photostimulation (Arenkiel et al., 2007; Wang et al., 2007) (Fig. 1B), Crh-Cre (Corticotropin Releasing Hormone-Cre) mice for EPL interneuron-specific labeling and/or photostimulation (Huang et al., 2013) (Fig. 1C), and Dlx5/6-Cre mice for targeting adult-born GCs (Kohwi et al., 2007) (Fig. 1D). Because GCs comprise a highly heterogeneous population of neurons that are born both during embryonic stages and throughout adulthood, Dlx5/6-Cre mice injected with conditional AAV engineered to express ChR2 (or Tom) afforded the ability to manipulate (or label) subsets of adult-born GCs selectively beyond embryonic periods. Through EdU pulse labeling of adult-born neurons colabeled with a flexed conditional GFP-expressing AAV, we validated that Dlx5/6Cre mice were useful for targeting reporter expression to young adult-born neurons (Fig. $1 E-G$ ). Together, these mouse lines allowed for cell-type-specific genetic targeting of different populations of neurons in the $\mathrm{OB}$ circuit.

\section{Photostimulation of neuronal subtypes with AOD-based scanning microscopy}

Having developed genetic models to target different neuronal subtypes selectively in the OB, we next established an AOD-based imaging microscope to assist in optogenetic circuit mapping through photostimulation of focal spots with high temporal resolution. For this, we used a BLM-series $473 \mathrm{~nm}$ solid-state blue laser system to generate stimulating laser foci (30 $\mu$ m diameter) and two AODs for controlling the focal position in a $2 \mathrm{D}$ plane (Fig. $2 A$ ). Using this system, we performed whole-cell recordings from targeted neurons in acute brain slices while simultaneously delivering focal laser illumination to presynaptic ChR2-expressing neurons in spatially restricted domains. Combining this approach and cell-type-specific expression of ChR2, we set out to reconstruct functional connectivity maps between genetically targeted neuronal subtypes by recording postsynaptic currents in neurons of interest while scanning laser light to stimulate presynaptic ChR2 + neurons (Fig. 2B)

To photostimulate ChR2 + neurons with high fidelity while at the same time achieving spatiotemporal resolution of focal illumination, we applied pulses of light at empirically determined optimal laser intensities $\left(\sim 20-40 \mathrm{~mW} / \mathrm{mm}^{2}\right.$; see the Materials and Methods), which enabled us to elicit single action potentials reliably from targeted ChR2-expressing neurons (Fig. 2C-E). The probability of eliciting action potentials in ChR2+ neurons decreased dramatically as the distance between the targeted soma and the stimulation spot increased (Fig. $2 \mathrm{~F}-\mathrm{H}$ ). Notably, photostimulation capable of driving cell-type-specific action potential firing fell below $50 \%$ when the distance exceeded $45 \mu \mathrm{m}$ from the targeted cell (Fig. $2 I-K$ ). This photostimulation system therefore enabled us to activate local ChR2 + neurons at resolvable spatial dimensions and within fast time windows for mapping patterns of functional connectivity.

\section{Functional mapping of MC-to-EPL interneuron and MC-to-GC connectivity}

Having established mouse models and an electrophysiological recording rig compatible for targeted scanning photostimula- 

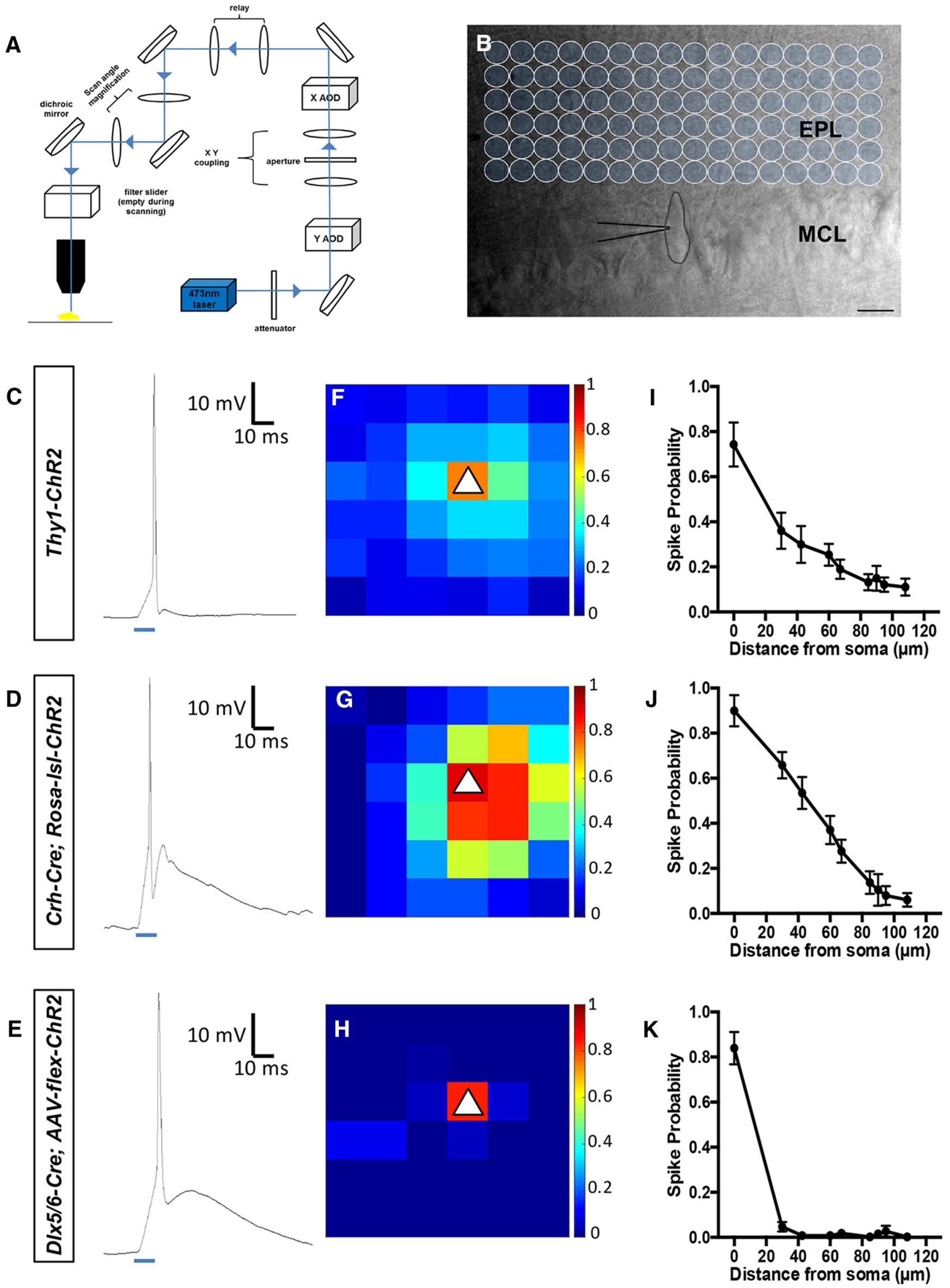
tion, we next sought to map the functional connectivity from MCs to either EPL interneurons or GCs to reveal the organization of excitatory connections onto interneuron subtypes in the OB. To first map MC input onto EPL interneurons, we generated Thy1-ChR2;Crh-Cre;ROSA-lsl-tdTomato mice, in which MCs expressed $\mathrm{ChR} 2$, and EPL interneurons were labeled in red. We prepared acute coronal slices from the $\mathrm{OB}$, took recordings from Tom + EPL interneurons and delivered randomized patterns of laser stimulation to different spots along the MCL (Fig. 3A). For reproducibility and statistical analysis, each stimulation site was visited five times. Connectivity from a given MCL stimulation spot was determined when we observed repeated and reliable evoked postsynaptic currents in the recorded EPL interneuron (Fig. 3B, see more in "Materials and Methods" section). Through this approach, we reconstructed a spatially defined connectivity map of MC input onto individual EPL interneurons, from which evoked PSC amplitudes for specified spots were calculated by averaging the amplitudes of all the evoked PSCs over multiple stimulation trials. Trials failing to elicit PSCs were not included. In a typical example of mapping MC-to-EPL interneuron connectivity (Fig. $3 C$ ), we observed that EPL interneurons received input from MCs between 0 and $500 \mu \mathrm{m}$ away, suggesting that EPL interneurons are broadly innervated by MC input.

To next map MC input onto GCs, we generated Thy1-ChR2; Dlx5/6-Cre mice and injected a conditional (flexed) tdTom AAV into the OB. The Dlx5/6-Cre driver line expresses Cre in maturing interneurons and reduces expression after interneurons have fully integrated into the OB (Fig. 1D-G) (Kohwi et al., 2007). Therefore, we implemented this mouse to selectively target migrating adult-born GCs in the OB while avoiding both neural stem cells and fully integrated mature GCs. Three weeks after viral injection, we took recordings from Tom + GCs ( $\sim 4$ weeks old) in acute coronal brain slices and performed light-assisted connectivity mapping from MCs (Fig. 3D). At this developmental stage, GCs have elaborate dendritic branches and dense spines and form synaptic connections with other components in the $\mathrm{OB}$ circuits (Petreanu and Alvarez-Buylla, 2002; Carleton et al., 2003). Similar to the mapping experiments from MC-to-EPL interneurons, we reconstructed connectivity maps onto individual GCs by monitoring evoked postsynaptic currents in response to focally targeted MC photostimulation (Fig. 3E,F). We found that GCs received weaker and narrower excitatory input from MCs compared with those observed between MCs and EPL interneurons.

To compare patterns of MC-to-interneuron connectivity statistically at a population level, we next analyzed data from all of the EPL interneuron-to-MC, and GC-to-MC pairs. Among 16

\footnotetext{
Figure 2. Optogenetic mapping of excitatory connections from MCs onto EPL interneurons and $G C S$ with a random-access $A O D$ scanning microscope system. $A$, Overview of the randomaccess based scanning microscope system. Light from a blue laser $(473 \mathrm{~nm})$ is attenuated and directed to an AOD-based 2D scanner. Scan angle of the laser beam is magnified and coupled into an upright research microscope. $\boldsymbol{B}$, Differential interference contrast image showing the experimental paradigm. Targeted cells were recorded in acute brain slices and postsynaptic currents were measured when ChR2 + cells in distinct spatial domains (blue circle) were activated. Individual spots were stimulated in random sequences to circumvent short-term synaptic modulation. Scale bar, $50 \mu \mathrm{m}$. C $-\boldsymbol{E}$, Photoactivation of MCs, Crh + interneurons, and GCs to elicit action potentials. Blue bar indicates the light stimulation period. $\boldsymbol{F}-\boldsymbol{H}$, Heat maps showing averaged spiking probability maps for photoactivation of EPL interneurons, GCs, and MCs. White triangles indicate locations of recorded (and stimulated) cell soma. Scale bar, $30 \mu \mathrm{m}$. $\boldsymbol{I}-\boldsymbol{K}$, Spiking probability of three different types of cells as functions of distance of the stimulating position from the recorded soma. $n=\sim 7-11$ cells. Error bars indicate SEM.
}

recorded GCs, nine of them did not receive any EPSCs from MCs, as detectable by our experimental approach, whereas all recorded EPL interneurons received robust excitation after MC stimulation. For each recorded neuron, we first determined its input peak, the stimulation spot that elicited the strongest postsynaptic currents. We then calculated the input strength (absolute or normalized to input peak) of different stimulation spots from the input peak to one of the two tangential sides as a function of distance from the input peak (Fig. 3) (EPL interneurons, 12 sides from $n=6$ cells; GCs, 14 sides from $n=7$ cells; GCs not receiving EPSCs were excluded from this analysis). We found that EPL interneurons received stronger and broader $\mathrm{MC}$ input than GCs (Fig. $3 G$ ) (2-way ANOVA test with repeated measures, main effect of group, $p=0.0001$; group $\times$ distance, $p=2 * 10^{-7}$ ), suggesting that these neurons are likely to be more active and are broadly tuned to odor stimuli.

\section{Functional mapping of EPL interneuron-to-MC or GC-to-MC connectivity}

Having shown that MCs made connections onto GCs and EPL interneurons with distinct patterns of connectivity, we next investigated the patterns of reciprocal connectivity between MCs and $\mathrm{OB}$ interneurons by mapping the inhibitory connections. For EPL interneuron-to-MC connectivity mapping, we generated Crh-Cre;ROSA-lsl-ChR2 mice, made acute coronal OB slices, and performed whole-cell recordings from MCs while photostimulating EPL interneurons. We used high $\mathrm{Cl}^{-}$internal solutions for recordings, held MCs at $-80 \mathrm{mV}$, and delivered light at defined spots within the EPL (Fig. $4 A$ ). In order not to compromise a significant component of MC dendrites during slice preparation, we included Alexa Fluor 594 dye in the internal solution and confirmed that the lateral dendrites of recorded neurons extended at least $500 \mu \mathrm{m}$ on each side (data not shown). We recorded light-evoked postsynaptic currents in MCs while photostimulating EPL interneurons (Fig. $4 B$ ) and reconstructed $2 \mathrm{D}$ connectivity maps. As shown in a representative example of an EPL interneuron-to-MC connectivity map (Fig. $4 C$ ), we routinely observed that MCs received inhibitory input from broadly distributed EPL interneurons.

Next, to map GC-to-MC connectivity, we used Dlx5/6-Cre mice and injected flexed ChR2 AAV into the OB to target ChR2 expression to young adult-born GCs. We then made coronal OB slices 3 weeks after viral injection, when targeted cells had integrated into the circuitry, delivered focal laser light at individual spots within the GC layer (GCL) (Fig. 4D), and recorded lightevoked postsynaptic currents in MCs (Fig. 4E). Similarly, we reconstructed GC-to-MC connectivity maps. Interestingly, in a typical example shown in Fig. 4F, MCs primarily received local inhibitory input from GCs, whereas EPL interneurons showed a much more distributed input (Fig. 4C).

We next analyzed the connectivity data from these interneuron subtype populations onto MCs. To quantify spatial distributions of the inhibitory input, particularly in the tangential axis, we calculated the average current amplitude of the stimulation spots as a function of the tangential distance for each recorded cell. We first assayed the average current amplitude of EPL interneuron inputs onto MCs based on tangential distance (Fig. 4G) (12 sides from $n=6$ cells). Due to the variability of absolute current values in GC-to-MC connectivity that resulted from viral expression, we normalized the current amplitudes for each recorded neuron in GC-to-MC and EPL interneuron-to-MC mapping experiments (Fig. $4 H$ ) (EPL-MC, 12 sides from $n=6$ cells; GC-MC, 27 sides from $n=14$ cells). We found a lower density (or probability) of 

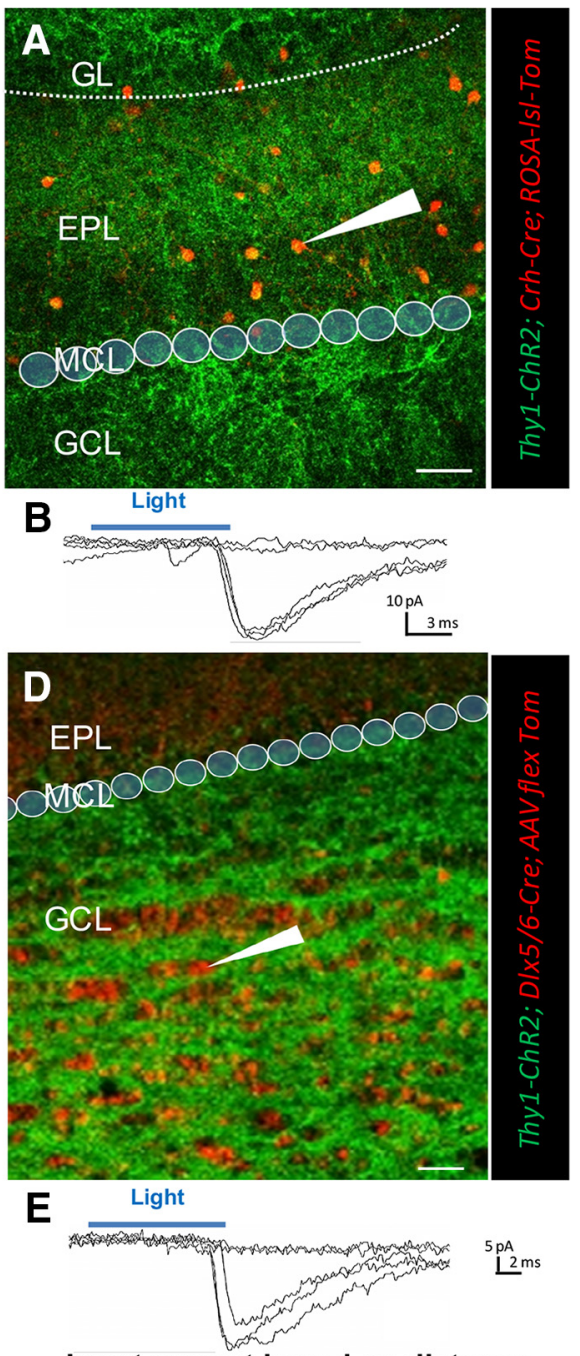

Input current based on distance between mitral cells and interneuron

G

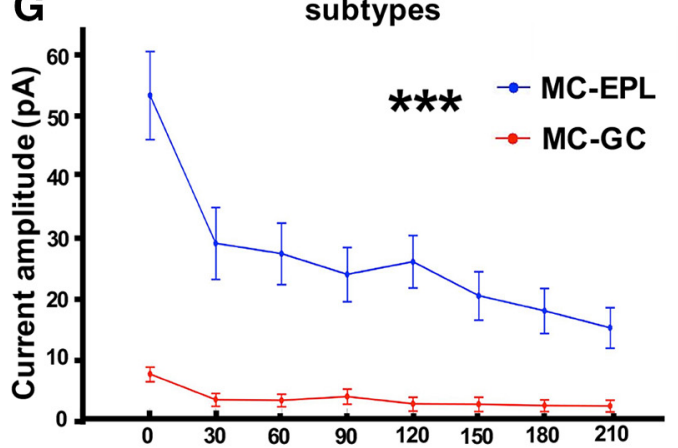

Tangential distance from input peak $(\mu \mathrm{m})$

\section{Distribution of mitral cell input onto an example EPL interneuron}

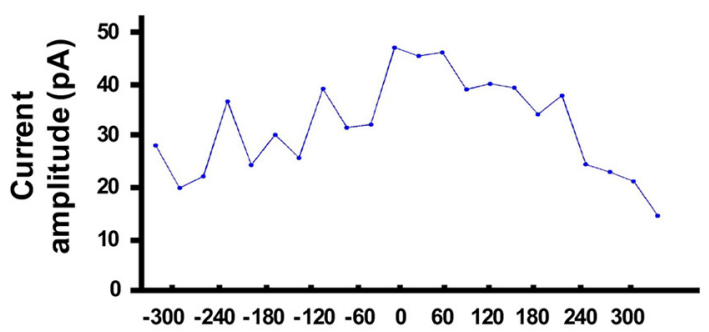

Tangential Distance from input peak $(\mu \mathrm{m})$

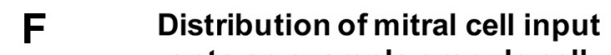
onto an example granule cell

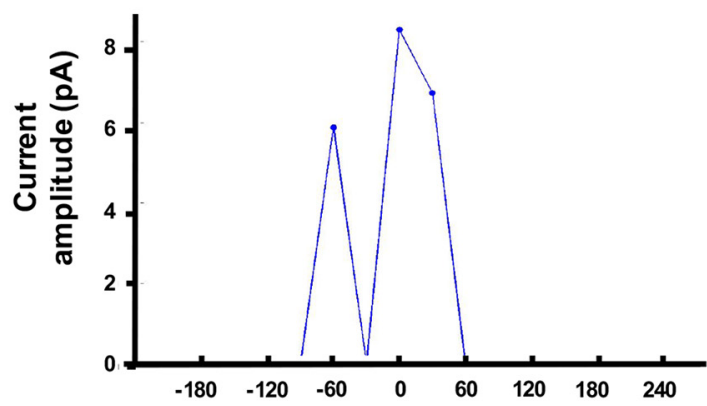

Tangential distance from input peak $(\mu \mathrm{m})$

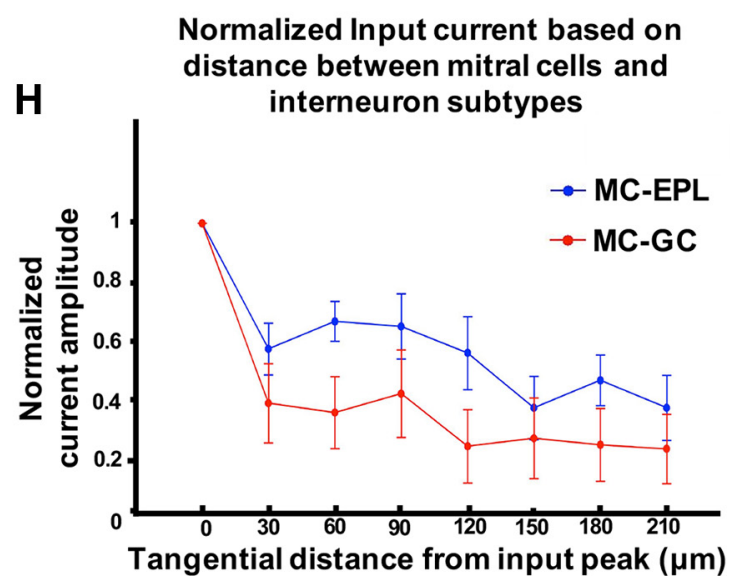

Figure 3. Average input current amplitude of $O B$ interneurons as a function of distance from the input peak. $A$, Diagram of the MC-to-EPL interneuron connectivity mapping experiment. White triangle indicates the recorded EPL interneuron. Blue circles indicate stimulation spots along the MC layer. During whole-cell recordings from the EPL interneuron, the laser beam stimulated these spots multiple times in random order. Scale bar, $50 \mu \mathrm{m} . \boldsymbol{B}$, Example showing the overlay of five recording traces from an EPL interneuron when the same spot in MCL was stimulated five times. Bar indicates the photostimulation period. C, Distribution of MC input onto an example EPL interneuron. D, Diagram showing the MC-to-GC connectivity mapping experiment. White triangle indicates the recorded GC. Blue circles indicate stimulation spots along the MC layer. During whole-cell recordings from the GC, the laser beam stimulated these spots multiple times in random order. Scale bar, $50 \mu \mathrm{m}$. $E$, Example showing the overlay of five recording traces from $\mathrm{GC}$ when the same spot in $\mathrm{MCL}$ was stimulated five times. Bar indicates the stimulation period. $\boldsymbol{F}$, Distribution of $M C$ input onto an example GC. $G$, Graph showing the differences of input currents between $M C s$ and $G C s$ and between MCS and EPL interneurons. ${ }^{* *} p<0.001$ (2-way ANOVA test with repeated measures). Error bars indicate SEM. $\boldsymbol{H}$, Graph showing normalized input current between MCs and $\mathrm{GCS}$ and between MCs and EPL interneurons. Current amplitude is normalized to the input peak. Error bars indicate SEM. 

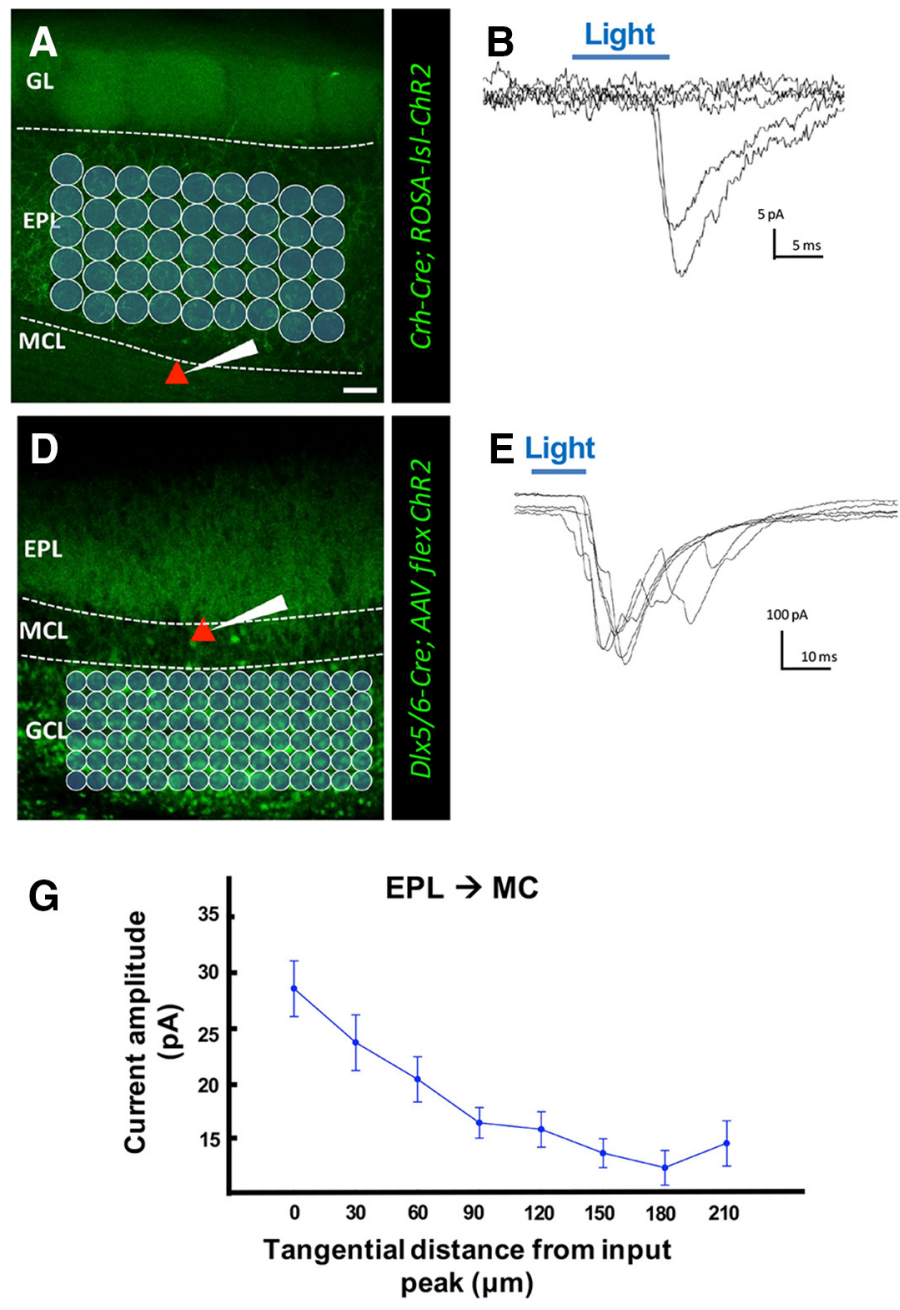

H
F

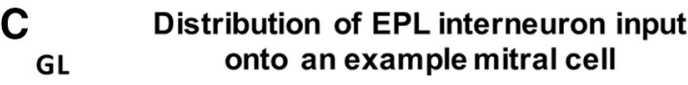

GL onto an example mitral cell

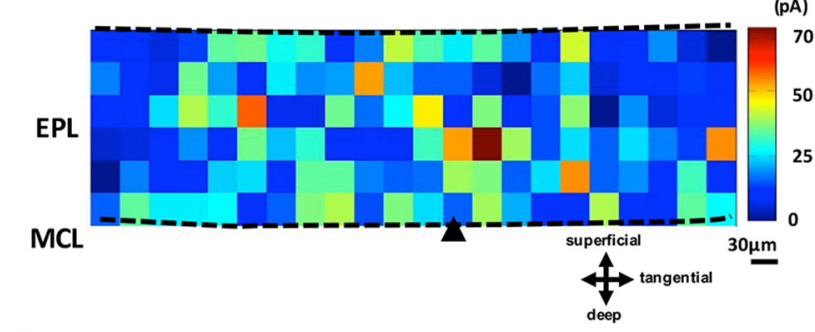

MCL

Distribution of granule cell input onto an example mitral cell
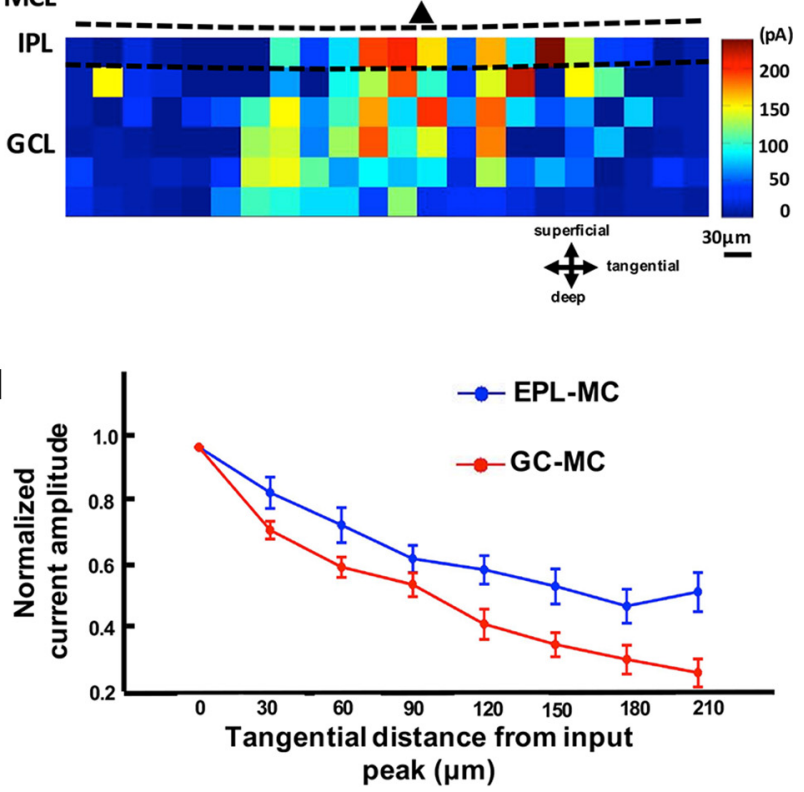

Figure 4. Local distribution of the inhibitory input from EPL interneurons/GCs to MCs. A, Diagram showing the EPL interneuron-to-MC connectivity mapping experiment. Red triangle indicates the recorded MC. Blue circles indicate stimulation spots within the EPL. During whole-cell recordings from the MC, the laser beam will stimulate these spots multiple times in random order. Scale bar, $30 \mu \mathrm{m} . \boldsymbol{B}$, Example showing the overlay of five recorded traces from a MC when the same spot was stimulated five times. Bar indicates the photostimulation period. $\boldsymbol{C}$, Heat map showing the distribution of EPL interneuron input on an example MC. Black triangle indicates the recorded MC. D, Diagram showing the GC-to-MC connectivity mapping experiment. Red triangle indicates the recorded MC. Blue circles indicate stimulation spots distributed in the $\mathrm{GCL}$. During whole-cell recordings from the MC, the laser beam stimulated these spots randomly multiple times. IPL, Internal plexiform layer. Scale bar, $30 \mu \mathrm{m}$. $\boldsymbol{E}$, Example showing the overlay of five recording traces from a MC when the same spot was stimulated five times. Bar indicates the photostimulation period. $\boldsymbol{F}$, Heat map showing the distribution of GC input onto an example MC. Black triangle indicates the recorded MC. G, Average EPL interneuron to MC input current amplitude as a function of distance from the input peak. Error bars indicate SEM. $\boldsymbol{H}$, Average normalized input current amplitude as a function of distance from the input peak. Error bars indicate SEM.

GC-to-MC connection versus EPL interneuron-to-MC connection as the tangential distances increased. Together, our experimental evidence suggests that MCs make broader and less specific functional connections with EPL interneurons than GCs, supporting models of how these two types of interneurons mediate different aspects of circuit computation and olfactory processing.

Connections between MCs and EPL interneurons retain patterns of connectivity after associative olfactory learning Neural circuits are highly plastic and both circuit structure and function can be modified by various factors, including neuromodulation, sensory experience, learning, and memory. Previous studies showed that GCs in the OB display plastic dynamics during odor enrichment or olfactory learning (Rochefort et al., 2002; Alonso et al., 2006; Mouret et al., 2008; Mouret et al., 2009; Arenkiel et al., 2011). However, it is not clear whether, or how, GC circuit connectivity maps might be remodeled by sensory experience. Moreover, our understanding of EPL interneuron circuit plasticity in the adult $\mathrm{OB}$ remains completely unknown. To ad- dress how sensory experience affects interneuron plasticity in $\mathrm{OB}$ circuits, we implemented an olfactory associative learning paradigm to investigate the potential for EPL interneuron-to-MC or GC-to-MC connections to exhibit dynamic plasticity. Toward this, we designed a Go-NoGo task in which mice were trained to lick a water port to receive a reward in response to "Odor A" (Go stimulus) and to refrain from responding to "Odor B" (NoGo stimulus) (Fig. 5A). Using this task, we mapped connectivity patterns when the percentage of correct responses reached the criteria $\geq 85 \%$ correct performance for 5 consecutive days (Fig. $5 B$ ). To record neurons that are involved in processing task-related odors selectively, we chose to use propionic acid (3-COOH) and butanol $(4-\mathrm{OH})$ as training odors. Previous studies in mice and rats using intrinsic signal imaging methods and immediate early gene analysis have shown that these two odors elicit responses in distinct regions in the dorsal surface of the OB; whereas neurons in anteromedial regions have been shown to respond to $3-\mathrm{COOH}$, those in anterolateral regions differentially respond to 4-OH (Uchida et al., 2000; Mori and Sakano, 2011). By perform- 
A

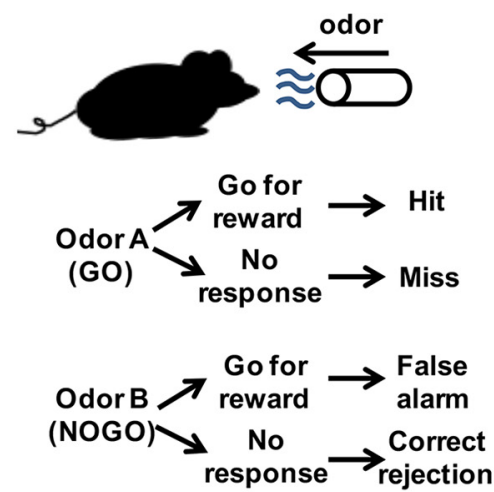

B

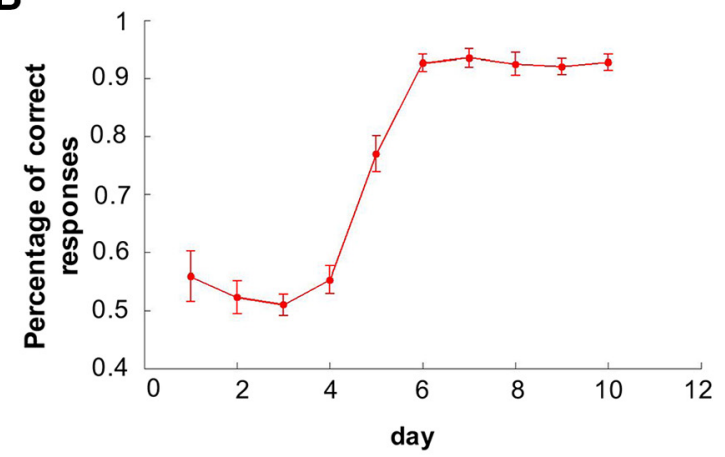

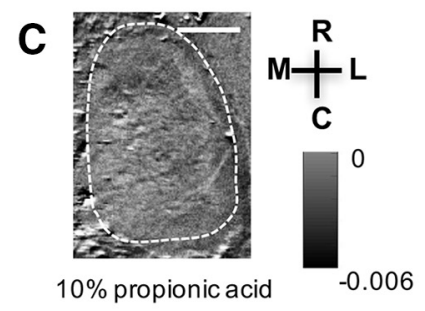

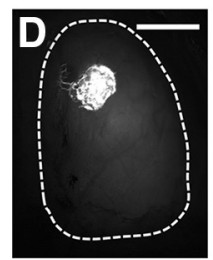

E
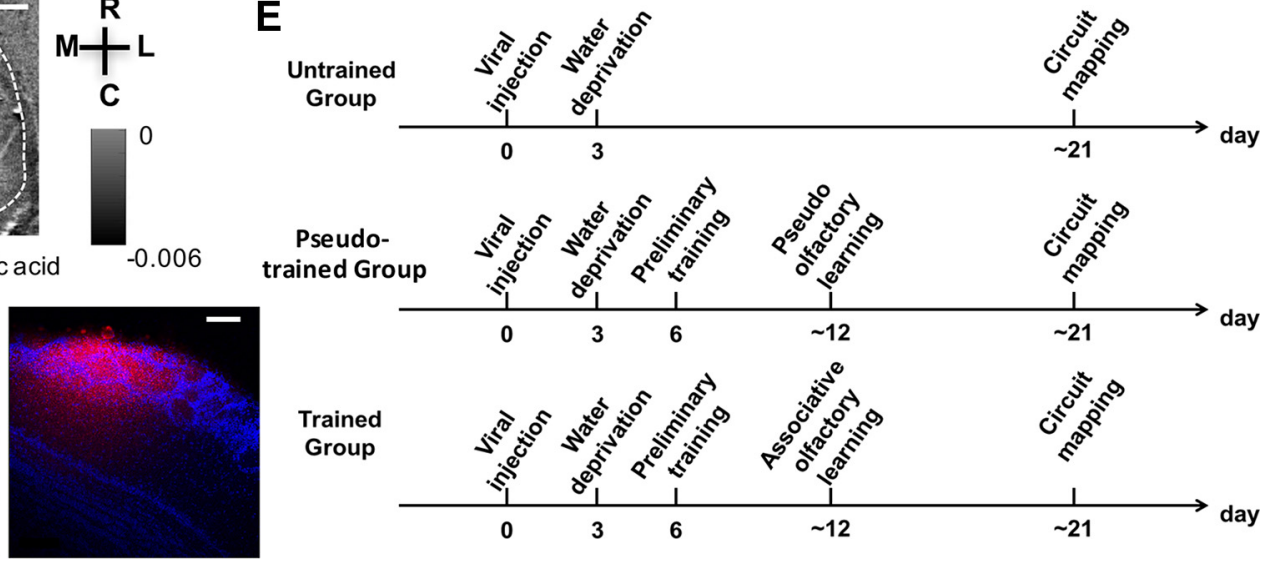

Figure 5. Associative learning to defined odorants allows mapping of olfactory circuit plasticity. $A$, Schematic of the associative olfactory learning training paradigm. $B$, Typical example showing the performance curve of one sample individual in the training group. This mouse started to perform at a correction rate $>85 \%$ after day $6 . N=\sim 10-18$ sessions in each day. Error bars indicate SEM. C, Intrinsic imaging showing representations of propionic acid in the dorsal surface OB. Typically, rostral-medial-dorsal regions showed responses to propionic acid. Scale bar, $1 \mathrm{~mm}$. M, Medial; L, lateral; R, rostral; C, caudal. Dashed lines show the outline of the OB. D, Left, Example image of Dil labeling of the activated region of the dorsal OB after intrinsic signal imaging. Scale bar, $1 \mathrm{~mm}$. Right, Coronal section of OB after Dil labeling. Scale bar, $100 \mu \mathrm{m}$. E, Timeline for olfactory learning and subsequent plasticity circuit mapping.

ing intrinsic imaging in the $\mathrm{OB}$, we first confirmed the previously described topographic maps for these two odorants (Fig. 5C, 4-OH not shown), which then enabled us to record connectivity maps from neurons that resided in 3-COOH/4-OH-responding regions in slices. For this experiment, we first located and labeled neuron populations that resided within the odor activation domains as revealed by intrinsic signal imaging (Fig. 5D). Mice were then subjected to Go/NoGo task training and functional connectivity was investigated via photostimulation and circuit mapping. Importantly, analysis of functional connectivity not only included the trained cohorts, but also control groups of both untrained and pseudotrained animals, and odorant stimulation was, respectively, not paired or was randomized to the task (Fig. 5E).

To investigate the potential plasticity of connectivity between EPL interneurons and MCs, we trained either Crh-Cre;ROSA-lslChR2 mice or Thy1-ChR2;Crh-Cre;ROSA-lsl-tdTom mice, and performed mapping experiments as described above. Statistical analysis showed that the main effect of different cell groups on the connectivity strength was not significant in either MC-to-EPL interneuron connectivity or EPL interneuron-to-MC connectivity, whereas there was a significant group $\times$ distance interaction in EPL interneuron-to-MC connectivity (Fig. 6A,B) (MC-toEPL, 12 sides from $n=6$ cells in the untrained group, 14 sides from $n=7$ Go odor cells, 18 sides from $n=9$ NoGo odor cells, and 15 sides from $n=8$ nonactivated cells in the trained group, 2-way ANOVA test with repeated measures, main effect of group, $p=0.3651$, group $\times$ distance interaction, $p=0.932 ;$ EPL-to-MC, 26 sides from $n=14$ cells in the untrained group, 13 sides from $n=7$ Go odor cells, 14 sides from $n=7$ NoGo odor cells, and 18 sides from $n=9$ nonactivated cells in the trained group, 2-way ANOVA test with repeated measures, main effect of group, $p=$ 0.0982, group $\times$ distance interaction, $p=0.0032$ ). Go-NoGo associative olfactory learning training did not reshape the connectivity strength between EPL interneurons and MCs globally, but MCs responding to the Go odor in the trained group received enhanced inhibitory input from proximal EPL interneurons. These findings suggest that broadly connected EPL interneurons receive hardwired connections from MCs, and provide moderately plastic output onto MCs, which may be more involved in nonodor specific, or less-selective olfactory processes such as MC gain control.

\section{Connectivity patterns between adult-born GCs and MCs} show experience-dependent plasticity

Having shown that EPL interneurons and MCs form stereotyped connectivity patterns, we next sought to investigate the plasticity of the connections between GCs and MCs. Previous studies have shown that learning and memory enhances adult-born GC survival in the OB (Alonso et al., 2006) and such enhancement is observed particularly in maturing GCs (Mouret et al., 2008) when dendrite branching, spine growth, and synapse formation occurs (Petreanu and Alvarez-Buylla, 2002; Carleton et al., 2003). However, it remains unclear whether GC turnover and renewal 

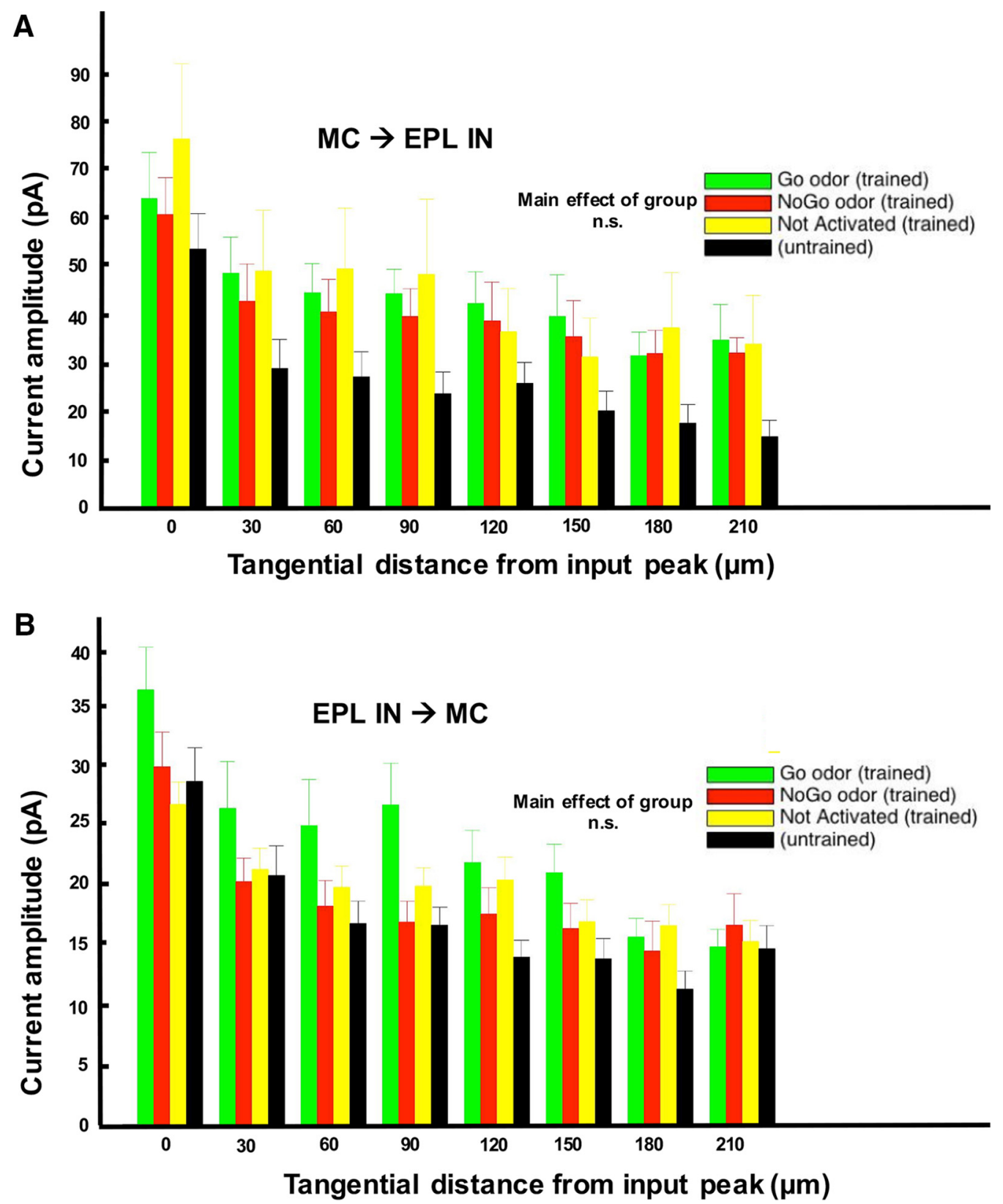

Figure 6. Functional connectivity mapping between EPL interneurons and MCs after olfactory learning. $A$, Excitatory connectivity patterns between MCs and EPL interneurons. The connection patterns do not change with olfactory learning. $\boldsymbol{B}$, Inhibitory connections in the reciprocal direction between EPL interneurons and MCs. n.s., No significance (two-way ANOVA with repeated measures). Error bars indicate SEM.

reshape MC connectivity patterns. To determine the effects of olfactory associative learning on GC connectivity maps during maturation, we used Thy1-ChR2;Dlx5/6-Cre mice that were injected with a flexed tdTomato AAV into the OB. Mice were trained $\sim 12 \mathrm{~d}$ after injection and, at $\sim 21 \mathrm{~d}$ after injection, we performed mapping experiments and compared the patterns of GC-to-MC connectivity with untrained or pseudotrained mice (Fig. 5E). Similar to what we found previously, a fraction of GCs failed to show any evoked EPSC with our approach (Fig. 7A). We excluded the subpopulation of unresponsive cells and analyzed the distribution of MC input amplitudes onto GCs as a function of distance from the input peak. First, we found that, after associative olfactory learning, there was a significant increase in the strength of excitatory synaptic input onto GCs within Go odor responding regions (see below for statistics) (Fig. 7B). Interest- ingly, we found that, in the pseudotrained group, neither cells in odor-activated regions nor cells in nonactivated regions showed significant differences from neurons in untrained animals (2-way ANOVA with repeated measures, 19 sides from $n=10$ Go odor cells, 15 sides from $n=8$ NoGo odor cells, 16 sides from $n=9$ nonactivated cells in the trained group; 23 sides from $n=12$ activated cells, 13 sides from $n=7$ nonactivated cells in the pseudotrained group; 14 sides from $n=7$ cells in the untrained group; main effect of group, $p=0.0148$; group $\times$ distance interaction, $p=0.4064$. Multiple comparison of the group effect, Fisher's least significant differences method, Go odor cells in the trained group vs NoGo odor cells in the trained group, $p=$ 0.0018 ; Go odor cells in the trained group vs nonactivated cells in the trained group, $p=0.0523$; Go odor cells in the trained group vs activated cells in the pseudotrained group, $p=0.0169$; Go odor 
A

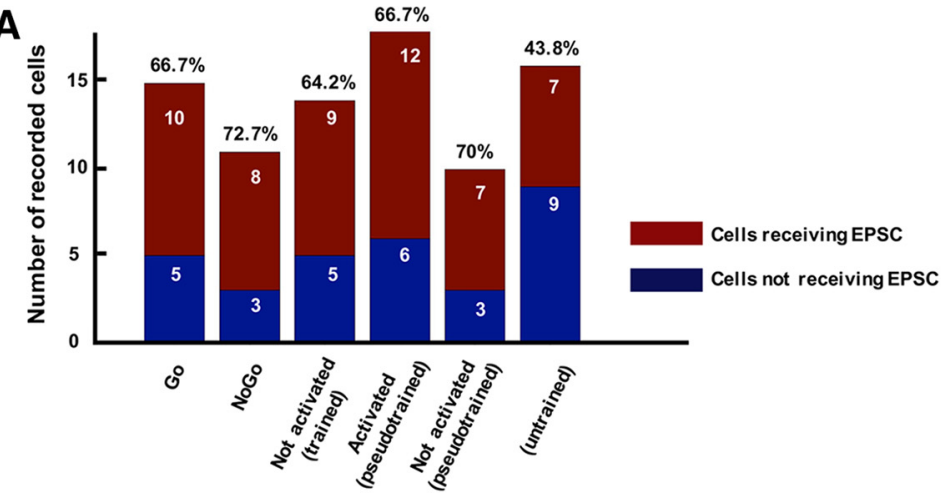

\section{B}
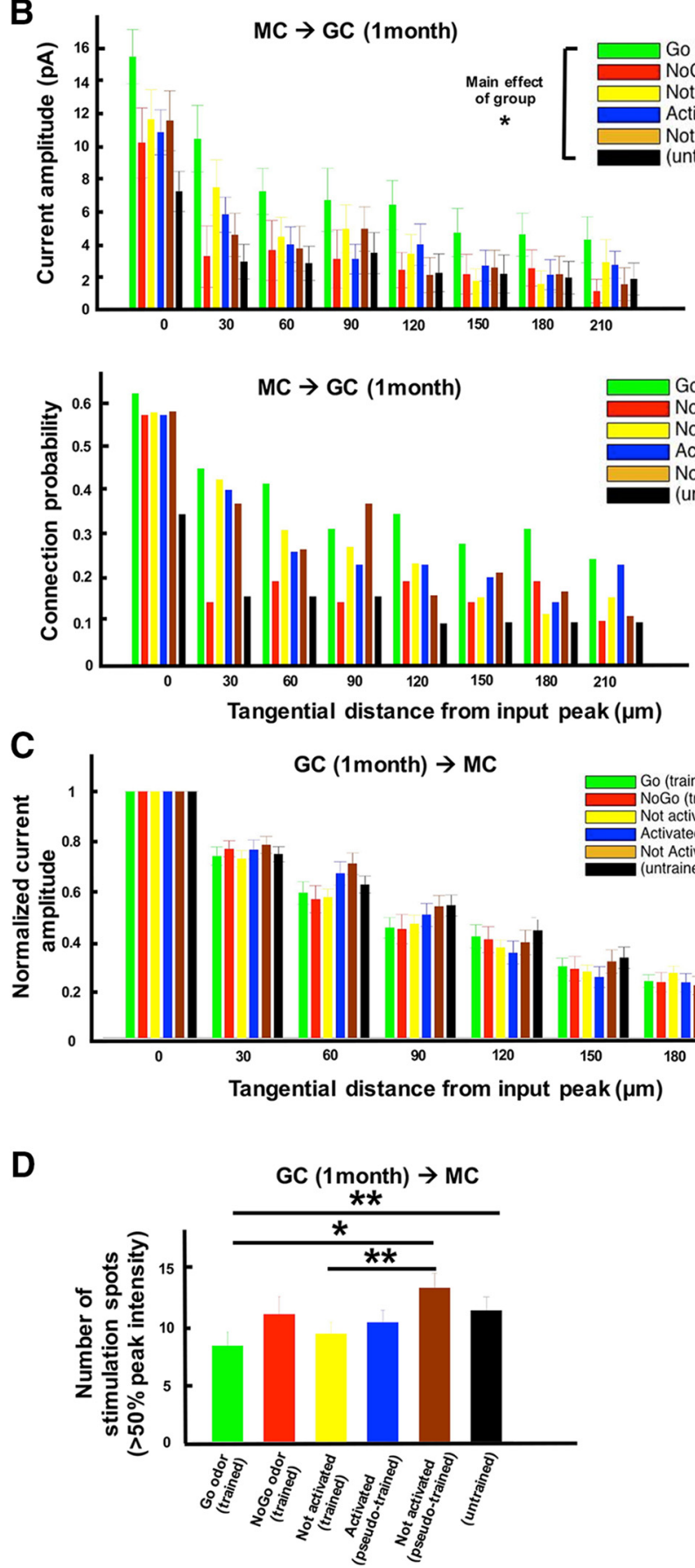

cells in the trained group vs nonactivated cells in the pseudotrained group, $p=$ 0.0293; Go odor cells in the trained group vs cells in the untrained group, $p=$ 0.0016 ; all the other pairs, $p>0.05$; Fig. $7 B)$. We also quantified the percentage of GCs that received input from MCs at different tangential distances (Fig. 7B). Together, these data suggest that, during olfactory learning, cells that responded to odors with positive valence received enhanced input from MCs and displayed experience-dependent plasticity to the associative learning task.

Next, we investigated whether adultborn GC output onto MCs showed changes in plasticity after associative odor learning. For this, we injected a flexed ChR2 AAV into the OBs of Dlx5/6-Cre mice to label young GCs and performed behavioral training and connectivity mapping. We used methods similar to those described above to analyze the data and plotted the distribution of normalized GC-to-MC current amplitude as a function of tangential distance for untrained versus trained or pseudotrained mice. (Fig. 7C). To further test whether learning reshapes the broadness of GC connectivity onto MCs, we calculated the number of stimulation spots with connectivity strength $>50 \%$ of the maximum connectivity strength among all the stimulation spots (calling it the "input peak") to each recorded MC. In this manner, we quantified the width or broadness of the inhibition distribution from GCs to MCs. For each recorded neuron, we counted the total number of stimulation spots ( $>50 \%$ input peak) in each $150 \mu \mathrm{m}$ (six stimulation spots

$\leftarrow$

Figure 7. Dynamic connectivity patterns between maturing GCS and MCs. $A$, Numbers of recorded GCs receiving/not receiving evoked EPSCs in different groups. White numbers are cell counts. Percentages of cells receiving evoked EPSCs over all recorded cells are shown above each bar. $\boldsymbol{B}$, Top, In the trained group, $\mathrm{GCS}$ receive more input from MCS ${ }^{*} p<0.05$; 2-way ANOVA test with repeated measures, multiple comparisons with Fisher's least significance difference method). Go odor cells in the trained group are significantly different from NoGo cells in the trained group and cells in the pseudotrained/untrained group $(p<0.05)$; differences between Go odor cells and nonactivated cells in the trained group are approaching the significance level ( $p=0.0523$ ); there is no significance between any other two groups. Error bars indicate SEM. Bottom, Percentage of GCs that respond to MC stimulation at different distances. Error bars indicate SEM. C, Tangential distribution of GC inhibition onto MCs in the trained, pseudotrained, and untrained animals. Error bars indicate SEM. $\boldsymbol{D}$, Numbers of stimulation spots with synaptic strength $>50 \%$ of the peak of cells in the trained, pseudotrained, and untrained groups. ${ }^{*} p<0.05,{ }^{* *} p<0.01$, one-way KruskalWallis ANOVA test, multiple-comparisons, Fisher's least significance difference method. Error bars indicate SEM. 
from superficial to deep GCL) $\times 210 \mu \mathrm{m}$ area (eight stimulation spots from the tangential input peak to one of the two tangential sides) and compared the numbers among different groups (Fig. 7D). Interestingly, we found that the number of stimulation spots $(>50 \%$ input peak) that evoked inhibitory currents in Go odor cells in the trained group was significantly lower than cells in the untrained group or nonactivated cells in the pseudotrained group, suggesting that learning reshapes the inhibitory connection patterns of GCs responding to odors associated with positive valence, making the inhibition distribution sharper and narrower. Moreover, we also observed a significant difference between nonactivated neurons in trained group and nonactivated neurons in the pseudotrained group, whereas NoGo odor cells in the trained group, the pseudotrained group, and the untrained group were not significantly different (Fig. 7D) (29 sides from $n=15$ Go odor cells, 25 sides from $n=13$ NoGo odor cells, and 42 sides from $n=21$ nonactivated cells in the trained group, 20 sides from $n=10$ activated cells, and 23 sides from $n=12$ nonactivated cells in the pseudotrained group, and 27 sides from $n=14$ cells in the untrained group; Kruskal-Wallis oneway ANOVA, $p=0.0147$; multiple-comparisons, Fisher's least significant difference method, Go odor cells in the trained group vs cells in the untrained group, $p=0.0332$; Go odor cells in the trained group vs nonactivated cells in the pseudotrained group, $p=0.0016$; nonactivated cells in the trained group vs nonactivated cells in the pseudotrained group, $p=0.0027$; all the other pairs, $p>0.05)$. This "sharpening" effect of GC inhibition was likely regulated by neural activity and odor valence, as well as some non-odor-specific modulations that were involved in olfactory learning tasks.

Evidence from the mapping experiments described above suggests that olfactory learning may influence the plasticity of adultborn GC connectivity patterns during GC maturation, so we next investigated whether experience-dependent plasticity was also observed in mature GCs. To train mice and subsequently record from mature adult-born GCs, we changed the experimental timeline (Fig. $8 A$ ) to investigate mature GC plasticity with the same experimental and analysis methods as above. Interestingly, we found that, with delayed learning, neither GC-to-MC nor MCto-GC connectivity displayed experience-dependent circuit remodeling (Fig. 8B-D; MC-to-GC, 2-way ANOVA with repeated measures, 18 sides from $n=11$ Go odor cells, 22 sides from $n=$ 12 NoGo odor cells, 17 sides from $n=10$ nonactivated cells in the trained group; 47 sides from $n=27$ cells in the untrained group; main effect of group, $p=0.9815$; group $\times$ distance interaction, $p=0.8309$; GC-to-MC, 19 sides from $n=10$ Go odor cells, 20 sides from $n=11$ NoGo odor cells, 23 sides from $n=12$ nonactivated cells in the trained group, 53 sides from $n=27$ cells in the untrained group; Kruskal-Wallis test for number of stimulation spots $>50 \%$ of peak intensity, $p=0.1667)$. Together, these experimental results suggest that GCs lack experience-dependent plasticity when they are mature and that a critical time period exists that allows adult-born GCs to adjust their connection patterns with synaptic partners, promoting circuit integration and information processing of relevant sensory stimuli.

\section{Discussion}

To better understand how neural circuits form and function, deducing patterns of microcircuit connectivity is essential. Here, using optogenetic-assisted mapping methods, we have begun to elucidate the functional connectivity patterns between MCs and two different populations of inhibitory interneurons in the mouse OB. Notably, we have characterized their general patterns of functional connectivity and shown that their connectivity maps display distinct changes to experiential learning (Fig. 9).
Both EPL interneurons and GCs make local inhibitory connections onto MCs but, compared with GCs, EPL connection patterns are broader and less specific. Regarding plasticity, EPL interneurons and MCs showed stereotyped or less plastic patterns of connectivity, whereas the circuitry between GCs and MCs was much more dynamic, particularly during GC maturation. Olfactory associative learning and neural activity can both influence GC plasticity; GCs that respond to odors with positive valence receive enhanced $\mathrm{MC}$ excitation after learning and associative olfactory learning experiences sharpen GC inhibitory output. Our study provides further insight into the organization and function of microcircuits within the $\mathrm{OB}$ and reveals potential mechanisms of how interneuron microcircuits might influence learning and memory.

\section{Mapping cell-type-specific patterns of microcircuit connectivity}

The nervous system consists of highly heterogeneous populations of neurons. These neurons form distinct patterns of connectivity with their synaptic partners, which determine the unique role of each neuron type in information processing. Recently, circuittracing techniques using engineered rabies virus have begun to reveal the structural connections between specified neuronal subtypes (Wickersham et al., 2007a; Wickersham et al., 2007b; Beier et al., 2011; Zampieri et al., 2014). However, this technique is still burdened by challenges that include difficulties in tracing from single starter neurons (Wickersham et al., 2007b; Rancz et al., 2011) and revealing a given synapse's nature and strength. Here, using genetically encoded optogenetic actuators, we have developed AOD-assisted circuit mapping methods that combine scanning photostimulation microscopy with cell-type specificity to map functional synaptic connectivity onto single postsynaptic neurons. Using this technique, we have begun to map functional patterns of connectivity between MCs and two types of inhibitory interneurons in the $\mathrm{OB}$, revealing distinct wiring and plasticity properties for each. However, in addition to MCs, GCs, and EPL interneurons, many other cell types reside in the $\mathrm{OB}$, including periglomerular cells (Livneh et al., 2009; Livneh et al., 2014), short-axon cells (Aungst et al., 2003; Eyre et al., 2008), Blanes cells (Pressler and Strowbridge, 2006), and external tufted cells (Gire et al., 2012). To understand the organization and function of the OB circuitry more fully, it will be necessary to further develop appropriate genetic drivers to map the connectivity of these other neuronal subpopulations.

\section{Plasticity of $\mathrm{OB}$ inhibitory circuits and their functional implications}

Neural circuit plasticity is a fundamental property of brain tissue, influencing a range of processes that include neural development, information processing, learning, and memory. Significant efforts have been made to investigate the plasticity of excitatory connections between principal neurons. However, even though inhibitory circuits also show plastic dynamics and play significant roles in circuit function, detailed investigation of inhibitory circuit plasticity has been relatively limited (Hensch et al., 1998; Hensch, 2005; Castillo et al., 2011; Kullmann et al., 2012). Due to GC neurogenesis and circuit integration during adulthood, the $\mathrm{OB}$ serves as a good model with which to investigate the plasticity of inhibitory connections. Here, by mapping OB inhibitory neuron connectivity in mice trained with associative olfactory learning, we showed that EPL interneurons and GCs display distinct forms of plasticity, each with unique functional implications. 
A
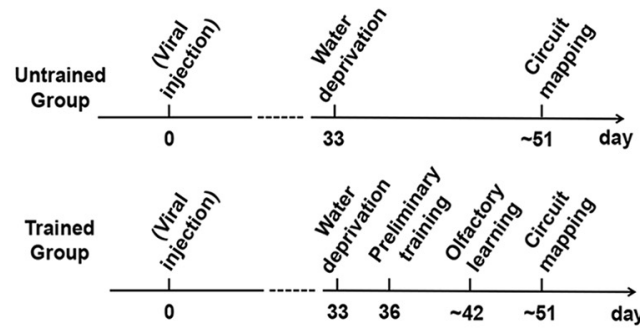

C

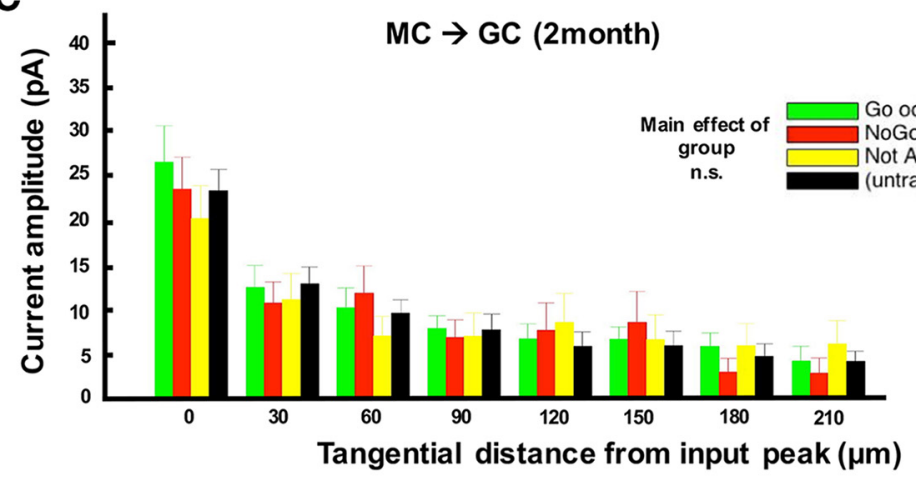

D

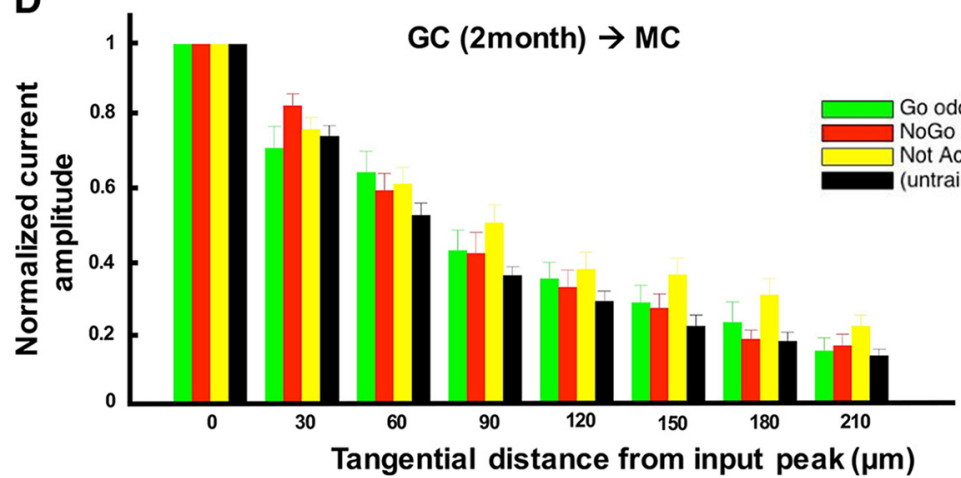

E

GC (2month) $\rightarrow$ MC

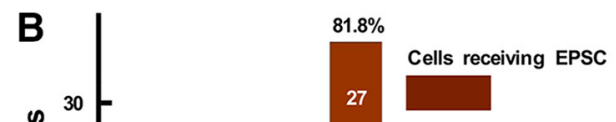

Cells not receiving EPSC
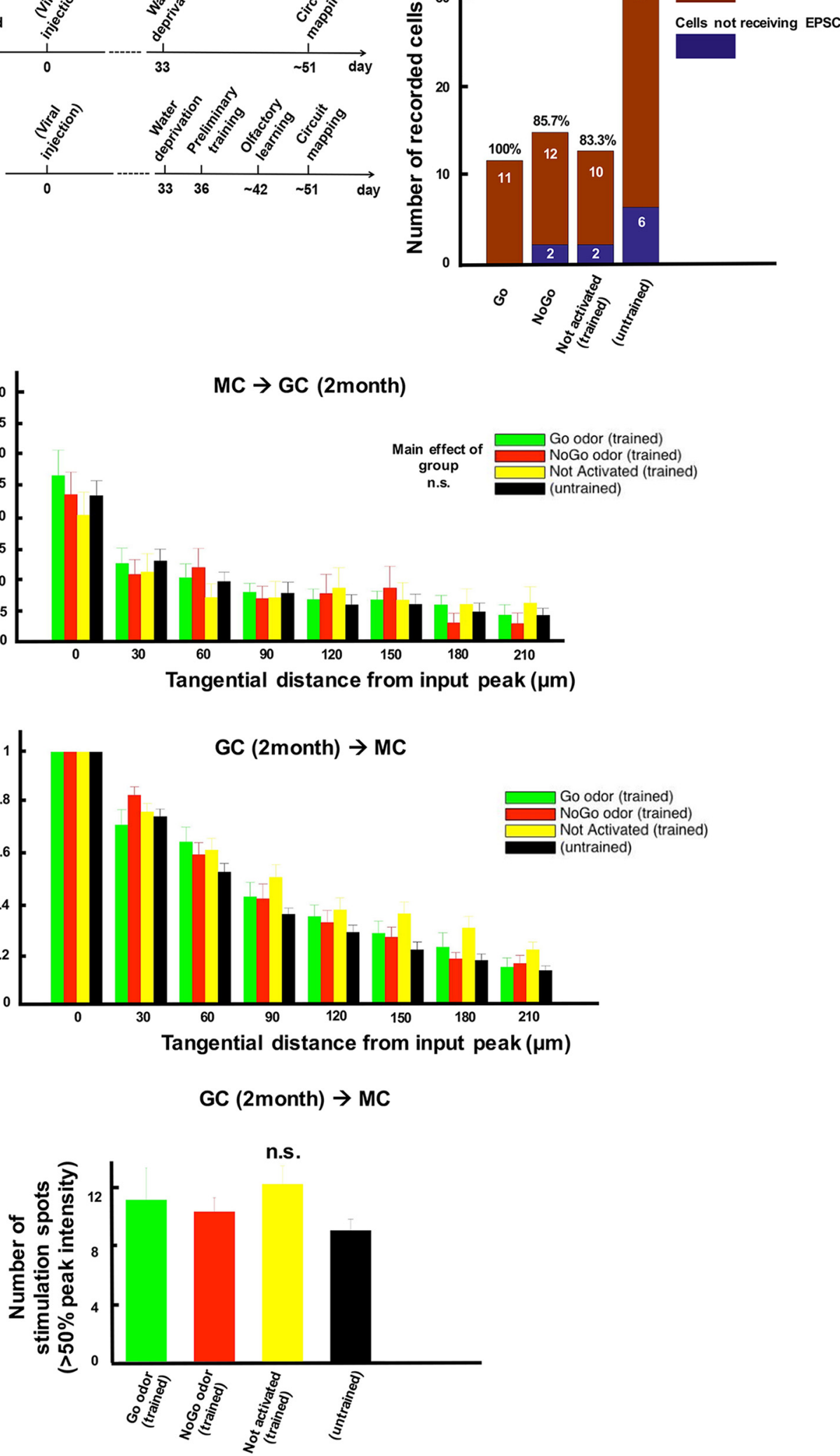

Figure 8. Mature adult-born GCs fail to show experience-dependent connectivity map plasticity. A, Experimental timeline for mapping functional circuit plasticity between mature GCs and MCs. $B$, Numbers of recorded GCs receiving/not receiving evoked EPSC in different groups. White numbers are cell counts. Percentages of cells receiving evoked EPSC over all recorded cells are shown above each bar. C, D, Connectivity patterns between MCs and mature GCs in trained, pseudotrained, and untrained animals. n.s., No significance (two-way ANOVA test with repeated measures). Error bars indicate SEM. E, Numbers of stimulation spots with synaptic strength $>50 \%$ of the peak of cells in the trained, pseuodotrained, and untrained groups. n.s., No significiance, one-way Kruskal-Wallis ANOVA test. Error bars indicate SEM. 
A

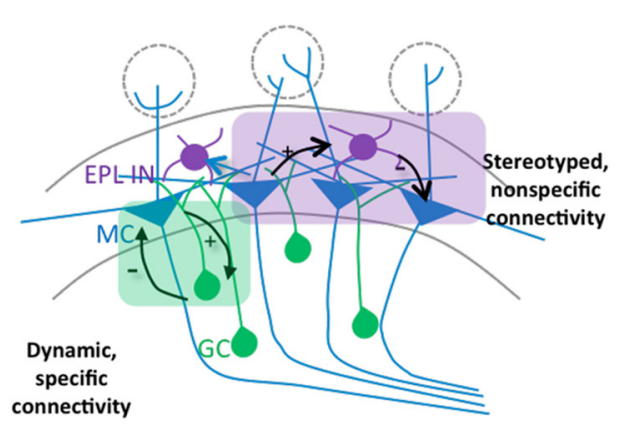

C
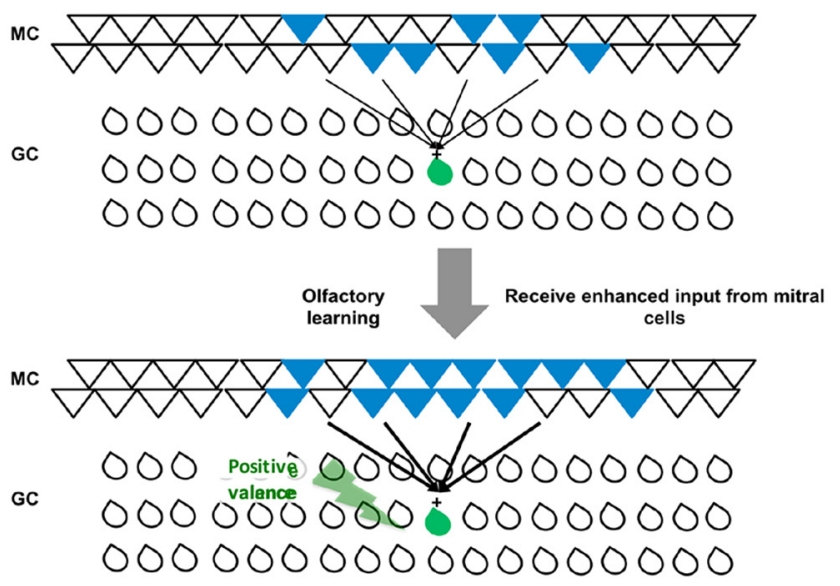

B $M C \leftrightarrow B P L$

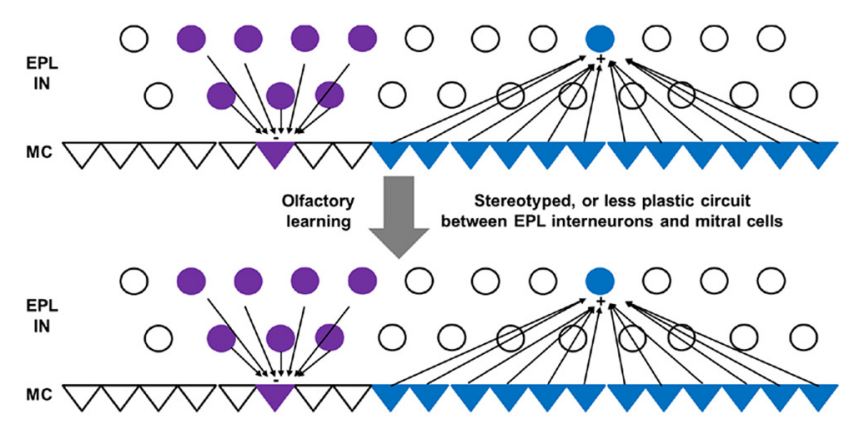

D GC $\rightarrow$ MC (1 month)
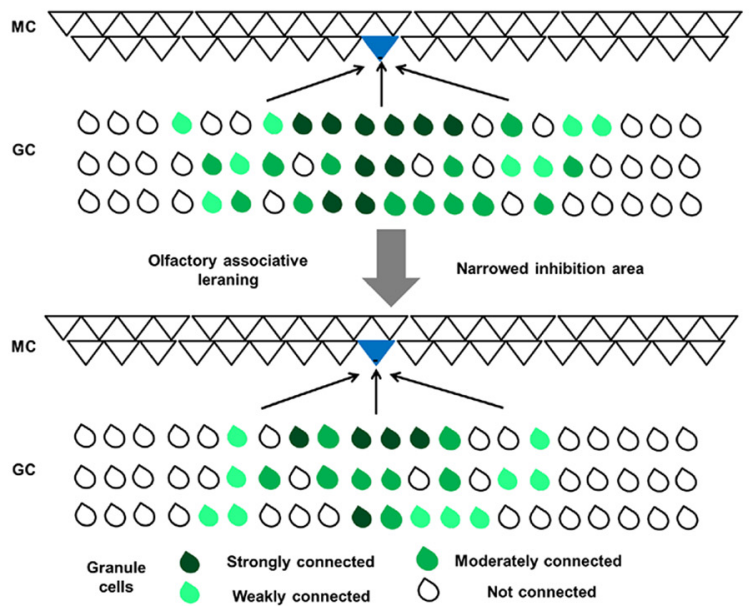

Figure 9. Model depicting the plasticity of distinct circuit connectivity maps in the OB. $A$, In OB circuits, both GCs and EPL interneurons make reciprocal connectivity with MCs. However, the EPL interneuron circuit is stereotyped and nonspecific, whereas GCs make dynamic and specific connectivity with MCs. B, Model diagram showing that EPL interneurons make broad connections with MCS. These connectivity patterns are stereotyped, or less plastic, during olfactory learning. C, Model diagram showing that GCs responding to reward-associated odors receive more and broader MCs after olfactory learning. $\boldsymbol{D}$, Model diagram showing that enriched olfactory experience reshapes $\mathrm{GC}$ inhibition, making it narrower and more specific.

Until recently, little was known about the function or plasticity of EPL interneurons in the OB (Lepousez et al., 2010; Huang et al., 2013; Kato et al., 2013; Miyamichi et al., 2013). Our data support the notion that EPL interneurons make reciprocal connectivity with MCs in a stereotyped, or less plastic, pattern, which is not dramatically affected by olfactory learning. Previously, EPL interneurons have been shown to modulate MC output linearly (Kato et al., 2013). Combining previous findings and our recent experimental evidence, these data collectively suggest that EPL interneurons receive broad, fixed connectivity from MCs and provide general inhibitory feedback to modulate MC activity levels. Therefore, this fixed circuitry may participate in MC gain control.

In contrast to EPL interneurons, GC circuitry is considered to be dynamic and adaptive (Rochefort et al., 2002; Carleton et al., 2003; Lledo et al., 2006; Arenkiel et al., 2011; Garcia et al., 2014). Previous data have shown that olfactory learning can significantly influence newborn GC survival rate and morphology (Alonso et al., 2006; Mouret et al., 2008) and that newborn GC activity facilitates learning and memory (Alonso et al., 2012). However, in the process of GC turnover, it remains unclear whether newly integrated cells establish novel connectivity patterns with MCs or simply replace the existing ones. Our findings show that olfactory associative learning enhances MC input onto GCs, which complements a recent study showing that GCs receive stronger centrifugal input from extrinsic higher brain regions after olfactory learning (Lepousez et al., 2014). Furthermore, our experimental evidence also suggests that GC inhibitory connectivity patterns are sharpened by neural activity. In mice trained with olfactory learning, some GCs make narrower and more specific inhibition onto MCs. This experience-dependent sharpening of inhibition may result from increased $\mathrm{OB}$ circuit activity, centrifugal input encoding valence information, and/or global neuromodulation to facilitate the formation of organized clusters of GC connectivity (Willhite et al., 2006).

Limited by our current method to identify different cell groups in the $\mathrm{OB}$ slices (large-scale intrinsic imaging to determine responding zones), we lacked reporters of neural activity and/or odor response profiles at single-cell resolution. We tried to lessen this limitation by choosing odors that activated relatively large and nonoverlapping areas in the $\mathrm{OB}$ and with topographic maps that have been reported and studied extensively with both imaging and histological methods (immediate early gene detection). We also used relatively high odor concentrations for training and imaging. Therefore, it was very likely that recorded neurons in the given zones were responding to certain odors in training. However, we cannot exclude the possibility that some neurons were misgrouped in our analysis, so an ideal experiment would be using activity-dependent fluorescent reporters to determine odor response profiles of recorded neurons.

By enhancing the excitatory input onto GCs and clustering GC inhibitory output, experience-dependent plasticity may facil- 
itate adult-born GC survival (Lin et al., 2010), circuit integration, and connectivity refinement. Regarding olfactory processing, whereas EPL interneurons may act to generally function in MC gain control, enhanced MC-to-GC excitation may allow tuning of inhibitory tone in specific MCs. Furthermore, clustering of GC output may also play significant roles in synchronizing MC output and facilitate information coding (Schoppa and Westbrook, 2001; Galán et al., 2006; Schoppa, 2006). To summarize, assaying interneuron connectivity patterns in the $\mathrm{OB}$ using light-assisted functional connectivity mapping has provided further insight into both stable modes of inhibition provided by EPL interneurons as well as the dynamic plasticity capacity afforded by the continual integration of newborn GCs.

\section{References}

Abraham NM, Egger V, Shimshek DR, Renden R, Fukunaga I, Sprengel R, Seeburg PH, Klugmann M, Margrie TW, Schaefer AT, Kuner T (2010) Synaptic inhibition in the olfactory bulb accelerates odor discrimination in mice. Neuron 65:399-411. CrossRef Medline

Alonso M, Viollet C, Gabellec MM, Meas-Yedid V, Olivo-Marin JC, Lledo PM (2006) Olfactory discrimination learning increases the survival of adult-born neurons in the olfactory bulb. J Neurosci 26:10508-10513. CrossRef Medline

Alonso M, Lepousez G, Sebastien W, Bardy C, Gabellec MM, Torquet N, Lledo PM (2012) Activation of adult-born neurons facilitates learning and memory. Nat Neurosci 15:897-904. CrossRef Medline

Arenkiel BR, Ehlers MD (2009) Molecular genetics and imaging technologies for circuit-based neuroanatomy. Nature 461:900-907. CrossRef Medline

Arenkiel BR, Peca J, Davison IG, Feliciano C, Deisseroth K, Augustine GJ, Ehlers MD, Feng G (2007) In vivo light-induced activation of neural circuitry in transgenic mice expressing channelrhodopsin-2. Neuron 54: 205-218. CrossRef Medline

Arenkiel BR, Hasegawa H, Yi JJ, Larsen RS, Wallace ML, Philpot BD, Wang F, Ehlers MD (2011) Activity-induced remodeling of olfactory bulb microcircuits revealed by monosynaptic tracing. PLoS One 6:e29423. CrossRef Medline

Aungst JL, Heyward PM, Puche AC, Karnup SV, Hayar A, Szabo G, Shipley MT (2003) Centre-surround inhibition among olfactory bulb glomeruli. Nature 426:623-629. CrossRef Medline

Beier KT, Saunders A, Oldenburg IA, Miyamichi K, Akhtar N, Luo L, Whelan SP, Sabatini B, Cepko CL (2011) Anterograde or retrograde transsynaptic labeling of CNS neurons with vesicular stomatitis virus vectors. Proc Natl Acad Sci U S A 108:15414-15419. CrossRef Medline

Buck L, Axel R (1991) A novel multigene family may encode odorant receptors: a molecular basis for odor recognition. Cell 65:175-187. CrossRef Medline

Carleton A, Petreanu LT, Lansford R, Alvarez-Buylla A, Lledo PM (2003) Becoming a new neuron in the adult olfactory bulb. Nat Neurosci 6 : 507-518. Medline

Castillo PE, Chiu CQ, Carroll RC (2011) Long-term plasticity at inhibitory synapses. Curr Opin Neurobiol 21:328-338. CrossRef Medline

Chen WR, Xiong W, Shepherd GM (2000) Analysis of relations between NMDA receptors and GABA release at olfactory bulb reciprocal synapses. Neuron 25:625-633. CrossRef Medline

Davison IG, Ehlers MD (2011) Neural circuit mechanisms for pattern detection and feature combination in olfactory cortex. Neuron 70:82-94. CrossRef Medline

Eyre MD, Antal M, Nusser Z (2008) Distinct deep short-axon cell subtypes of the main olfactory bulb provide novel intrabulbar and extrabulbar GABAergic connections. J Neurosci 28:8217-8229. CrossRef Medline

Fino E, Yuste R (2011) Dense inhibitory connectivity in neocortex. Neuron 69:1188-1203. CrossRef Medline

Galán RF, Fourcaud-Trocmé N, Ermentrout GB, Urban NN (2006) Correlation-induced synchronization of oscillations in olfactory bulb neurons. J Neurosci 26:3646-3655. CrossRef Medline

Garcia I, Quast KB, Huang L, Herman AM, Selever J, Deussing JM, Justice NJ, Arenkiel BR (2014) Local CRH signaling promotes synaptogenesis and circuit integration of adult-born neurons. Dev Cell 30:645-659. CrossRef Medline
Ghosh S, Larson SD, Hefzi H, Marnoy Z, Cutforth T, Dokka K, Baldwin KK (2011) Sensory maps in the olfactory cortex defined by long-range viral tracing of single neurons. Nature 472:217-220. CrossRef Medline

Gire DH, Franks KM, Zak JD, Tanaka KF, Whitesell JD, Mulligan AA, Hen R, Schoppa NE (2012) Mitral cells in the olfactory bulb are mainly excited through a multistep signaling path. J Neurosci 32:2964-2975. CrossRef Medline

Hensch TK (2005) Critical period plasticity in local cortical circuits. Nat Rev Neurosci 6:877-888. Medline

Hensch TK, Fagiolini M, Mataga N, Stryker MP, Baekkeskov S, Kash SF (1998) Local GABA circuit control of experience-dependent plasticity in developing visual cortex. Science 282:1504-1508. CrossRef Medline

Huang L, Garcia I, Jen HI, Arenkiel BR (2013) Reciprocal connectivity between mitral cells and external plexiform layer interneurons in the mouse olfactory bulb. Front Neural Circuits 7:32. CrossRef Medline

Isaacson JS, Strowbridge BW (1998) Olfactory reciprocal synapses: dendritic signaling in the CNS. Neuron 20:749-761. CrossRef Medline

Iyer V, Hoogland TM, Saggau P (2006) Fast functional imaging of single neurons using random-access multiphoton (RAMP) microscopy. J Neurophysiol 95:535-545. Medline

Jacob V, Petreanu L, Wright N, Svoboda K, Fox K (2012) Regular spiking and intrinsic bursting pyramidal cells show orthogonal forms of experience-dependent plasticity in layer $\mathrm{V}$ of barrel cortex. Neuron 73 : 391-404. CrossRef Medline

Kandel ER, Markram H, Matthews PM, Yuste R, Koch C (2013) Neuroscience thinks big (and collaboratively). Nat Rev Neurosci 14:659-664. CrossRef Medline

Kato HK, Gillet SN, Peters AJ, Isaacson JS, Komiyama T (2013) Parvalbumin-expressing interneurons linearly control olfactory bulb output. Neuron 80:1218-1231. CrossRef Medline

Kätzel D, Zemelman BV, Buetfering C, Wölfel M, Miesenböck G (2011) The columnar and laminar organization of inhibitory connections to neocortical excitatory cells. Nat Neurosci 14:100-107. CrossRef Medline

Kohwi M, Petryniak MA, Long JE, Ekker M, Obata K, Yanagawa Y, Rubenstein JL, Alvarez-Buylla A (2007) A subpopulation of olfactory bulb GABAergic interneurons is derived from Emx1- and Dlx5/6-expressing progenitors. J Neurosci 27:6878-6891. CrossRef Medline

Kullmann DM, Moreau AW, Bakiri Y, Nicholson E (2012) Plasticity of inhibition. Neuron 75:951-962. CrossRef Medline

Lepousez G, Csaba Z, Bernard V, Loudes C, Videau C, Lacombe J, Epelbaum J, Viollet C (2010) Somatostatin interneurons delineate the inner part of the external plexiform layer in the mouse main olfactory bulb. J Comp Neurol 518:1976-1994. CrossRef Medline

Lepousez G, Nissant A, Bryant AK, Gheusi G, Greer CA, Lledo PM (2014) Olfactory learning promotes input-specific synaptic plasticity in adult-born neurons. Proc Natl Acad Sci U S A 111:13984-13989. CrossRef Medline

Lin CW, Sim S, Ainsworth A, Okada M, Kelsch W, Lois C (2010) Genetically increased cell-intrinsic excitability enhances neuronal integration into adult brain circuits. Neuron 65:32-39. CrossRef Medline

Lin da Y, Shea SD, Katz LC (2006) Representation of natural stimuli in the rodent main olfactory bulb. Neuron 50:937-949. CrossRef Medline

Livneh Y, Feinstein N, Klein M, Mizrahi A (2009) Sensory input enhances synaptogenesis of adult-born neurons. J Neurosci 29:86-97. CrossRef Medline

Livneh Y, Adam Y, Mizrahi A (2014) Odor processing by adult-born neurons. Neuron 81:1097-1110. CrossRef Medline

Lledo PM, Alonso M, Grubb MS (2006) Adult neurogenesis and functional plasticity in neuronal circuits. Nat Rev Neurosci 7:179-193. CrossRef Medline

Miyamichi K, Amat F, Moussavi F, Wang C, Wickersham I, Wall NR, Taniguchi H, Tasic B, Huang ZJ, He Z, Callaway EM, Horowitz MA, Luo L (2011) Cortical representations of olfactory input by trans-synaptic tracing. Nature 472:191-196. CrossRef Medline

Miyamichi K, Shlomai-Fuchs Y, Shu M, Weissbourd BC, Luo L, Mizrahi A (2013) Dissecting local circuits: parvalbumin interneurons underlie broad feedback control of olfactory bulb output. Neuron 80:1232-1245. CrossRef Medline

Mombaerts P, Wang F, Dulac C, Chao SK, Nemes A, Mendelsohn M, Edmondson J, Axel R (1996) Visualizing an olfactory sensory map. Cell 87:675-686. CrossRef Medline

Monory K, Massa F, Egertová M, Eder M, Blaudzun H, Westenbroek R, Kelsch W, Jacob W, Marsch R, Ekker M, Long J, Rubenstein JL, Goebbels 
S, Nave KA, During M, Klugmann M, Wölfel B, Dodt HU, Zieglgänsberger W, Wotjak CT, et al. (2006) The endocannabinoid system controls key epileptogenic circuits in the hippocampus. Neuron 51:455-466. CrossRef Medline

Mori K, Sakano H (2011) How is the olfactory map formed and interpreted in the mammalian brain? Annu Rev Neurosci 34:467-499. CrossRef Medline

Mouret A, Gheusi G, Gabellec MM, de Chaumont F, Olivo-Marin JC, Lledo PM (2008) Learning and survival of newly generated neurons: when time matters. J Neurosci 28:11511-11516. CrossRef Medline

Mouret A, Lepousez G, Gras J, Gabellec MM, Lledo PM (2009) Turnover of newborn olfactory bulb neurons optimizes olfaction. J Neurosci 29: 12302-12314. CrossRef Medline

Murphey DK, Herman AM, Arenkiel BR (2014) Dissecting inhibitory brain circuits with genetically-targeted technologies. Front Neural Circuits 8:124. Medline

Petreanu L, Alvarez-Buylla A (2002) Maturation and death of adult-born olfactory bulb granule neurons: role of olfaction. J Neurosci 22:61066113. Medline

Pressler RT, Strowbridge BW (2006) Blanes cells mediate persistent feedforward inhibition onto granule cells in the olfactory bulb. Neuron 49: 889-904. CrossRef Medline

Price JL, Powell TP (1970a) The synaptology of the granule cells of the olfactory bulb. J Cell Sci 7:125-155. Medline

Price JL, Powell TP (1970b) The morphology of the granule cells of the olfactory bulb. J Cell Sci 7:91-123. Medline

Rancz EA, Franks KM, Schwarz MK, Pichler B, Schaefer AT, Margrie TW (2011) Transfection via whole-cell recording in vivo: bridging single-cell physiology, genetics and connectomics. Nat Neurosci 14:527-532. CrossRef Medline

Rochefort C, Gheusi G, Vincent JD, Lledo PM (2002) Enriched odor exposure increases the number of newborn neurons in the adult olfactory bulb and improves odor memory. J Neurosci 22:2679-2689. Medline

Schoppa NE (2006) Synchronization of olfactory bulb mitral cells by precisely timed inhibitory inputs. Neuron 49:271-283. CrossRef Medline
Schoppa NE, Westbrook GL (2001) Glomerulus-specific synchronization of mitral cells in the olfactory bulb. Neuron 31:639-651. CrossRef Medline

Schoppa NE, Kinzie JM, Sahara Y, Segerson TP, Westbrook GL (1998) Dendrodendritic inhibition in the olfactory bulb is driven by NMDA receptors. J Neurosci 18:6790-6802. Medline

Tan J, Savigner A, Ma M, Luo M (2010) Odor information processing by the olfactory bulb analyzed in gene-targeted mice. Neuron 65:912-926. CrossRef Medline

Taniguchi H, He M, Wu P, Kim S, Paik R, Sugino K, Kvitsani D, Fu Y, Lu J, Lin Y, Miyoshi G, Shima Y, Fishell G, Nelson SB, Huang ZJ (2011) A resource of Cre driver lines for genetic targeting of GABAergic neurons in cerebral cortex. Neuron 71:995-1013. CrossRef Medline

Uchida N, Takahashi YK, Tanifuji M, Mori K (2000) Odor maps in the mammalian olfactory bulb: domain organization and odorant structural features. Nat Neurosci 3:1035-1043. CrossRef Medline

Wang H, Peca J, Matsuzaki M, Matsuzaki K, Noguchi J, Qiu L, Wang D, Zhang F, Boyden E, Deisseroth K, Kasai H, Hall WC, Feng G, Augustine GJ (2007) High-speed mapping of synaptic connectivity using photostimulation in Channelrhodopsin-2 transgenic mice. Proc Natl Acad Sci U S A 104:8143-8148. CrossRef Medline

Wickersham IR, Finke S, Conzelmann KK, Callaway EM (2007a) Retrograde neuronal tracing with a deletion-mutant rabies virus. Nat Methods 4:47-49. CrossRef Medline

Wickersham IR, Lyon DC, Barnard RJ, Mori T, Finke S, Conzelmann KK, Young JA, Callaway EM (2007b) Monosynaptic restriction of transsynaptic tracing from single, genetically targeted neurons. Neuron 53: 639-647. CrossRef Medline

Willhite DC, Nguyen KT, Masurkar AV, Greer CA, Shepherd GM, Chen WR (2006) Viral tracing identifies distributed columnar organization in the olfactory bulb. Proc Natl Acad Sci U S A 103:12592-12597. CrossRef Medline

Zampieri N, Jessell TM, Murray AJ (2014) Mapping sensory circuits by anterograde transsynaptic transfer of recombinant rabies virus. Neuron 81: 766-778. CrossRef Medline 